\title{
PBK/TOPK, a Proliferating Neural Progenitor-Specific Mitogen-Activated Protein Kinase Kinase
}

\author{
J. D. Dougherty, ${ }^{1,2,3}$ A. D. R. Garcia, ${ }^{5}$ I. Nakano, ${ }^{3,4,6}$ M. Livingstone, ${ }^{7}$ B. Norris, ${ }^{7}$ R. Polakiewicz, ${ }^{7}$ E. M. Wexler, ${ }^{2,6}$, \\ M. V. Sofroniew, ${ }^{5}$ H. I. Kornblum, ${ }^{3,4,6}$ and D. H. Geschwind ${ }^{1,2,3,6}$ \\ ${ }^{1}$ Interdepartmental Program in the Neurosciences, ${ }^{2}$ Program in Neurogenetics, Neurology Department, ${ }^{3}$ Neural Stem Cell Research Center, ${ }^{4}$ Departments \\ of Molecular and Medical Pharmacology and Pediatrics, ${ }^{5}$ Department of Neurobiology and Brain Research Institute, and ${ }^{6}$ Department of Psychiatry and \\ Biobehavioral Sciences, David Geffen School of Medicine, University of California at Los Angeles, Los Angeles, California 90095-1769, and 7 Cell Signaling \\ Technology, Beverly, Massachusetts, 01915
}

We performed genomic subtraction coupled to microarray-based gene expression profiling and identified the PDZ (postsynaptic density95/Discs large/zona occludens-1)-binding kinase/T-LAK (lymphokine-activated killer T cell) cell originating protein kinase (PBK/TOPK) as a gene highly enriched in neural stem cell cultures. Previous studies have identified PBK/TOPK as a mitogen-activated protein kinase (MAPK) kinase that phosphorylated P38 MAPK but with no known expression or function in the nervous system. First, using a novel, bioinformatics-based approach to assess cross-correlation in large microarray datasets, we generated the hypothesis of a cell-cyclerelated role for PBK/TOPK in neural cells. We then demonstrated that both PBK/TOPK and P38 are activated in a cell-cycle-dependant manner in neuronal progenitor cells in vitro, and inhibition of this pathway disrupts progenitor proliferation and self-renewal, a core feature of progenitors. In vivo, PBK/TOPK is expressed in rapidly proliferating cells in the adult subependymal zone (SEZ) and early postnatal cerebellar external granular layer. Using an approach based on transgenically targeted ablation and lineage tracing in mice, we show that PBK/TOPK-positive cells in the SEZ are GFAP negative but arise from GFAP-positive neural stem cells during adult neurogenesis. Furthermore, ablation of the adult stem cell population leads to concomitant loss of PBK/TOPK-positive cells in the SEZ. Together, these studies demonstrate that PBK/TOPK is a marker for transiently amplifying neural progenitors in the SEZ. Additionally, they suggest that PBK/TOPK plays an important role in these progenitors, and further implicates the P38 MAPK pathway in general, as an important regulator of progenitor proliferation and self-renewal.

Key words: subventricular zone; microarray; neural stem cell; progenitor cell; P38 MAPK; external granular layer; rostral migratory stream

\section{Introduction}

Neural stem cells (NSCs) are an endogenous, self-renewing population of cells capable of generating all major cell types of the CNS (Lendahl et al., 1990; Reynolds and Weiss, 1992; Capela and Temple, 2002). NSCs exist throughout the germinal zones of the developing embryonic brain and persist into adulthood, providing for ongoing neurogenesis in select regions of the mammalian brain, offering hope for neural repair strategies (Palmer et al., 1999; Gage, 2000; Lie et al., 2004; Morshead and van der Kooy, 2004). Despite their rich potential for therapeutic applications, research on NSCs has been hampered by a lack of markers to identify NSCs prospectively and an incomplete understanding of

Received May 19, 2005; revised Sept. 29, 2005; accepted 0ct. 3, 2005.

This work was supported by National Institutes of Health Grants MH65756, NS47386, and NSO42693 and the Ron Shapiro Foundation. J.D.D. is supported by a Howard Hughes Medical Institute predoctoral fellowship. We thank Chris Evans, Kelsey Martin, Steve Horvath, and Chiara Sabatti for advice and editorial assistance. We also thank Robert Wechsler-Reya (Duke University) for the cerebellar granule cell culture protocol; Mathew Schibler (Carol Moss Spivak Cell Imaging Facility) and Dorwin Birt (Mental Retardation Research Core) for training and advice with confocal microscopy; Ingrid Schmid and Michael Gulrajani (University of California at Los Angeles Flow Cytometry Core) for training and advice with cytometry; Amir Abu Khalil for technical assistance; and Jeff Gotts for tissue. We are especially grateful to Alain Viel and Robert Lue (Harvard University) for generosity with anti-PBK serum.

Correspondence should be addressed to Daniel Geschwind, Department of Neurology, University of California at Los Angeles, 710 Westwood Plaza, Los Angeles, CA 90095. E-mail: dhg@ucla.edu.

D0I:10.1523/JNEUROSCI.3207-05.2005

Copyright $\odot 2005$ Society for Neuroscience ～0270-6474/05/2510773-13\$15.00/0 the pathways involved in the regulation of their proliferation and differentiation (Anderson, 2001; Lindvall et al., 2004).

To identify genes involved in NSC proliferation and differentiation, we performed extensive analysis of the gene expression in neural stem and progenitor cell cultures (Geschwind et al., 2001; Karsten et al., 2003). To provide additional functional annotation that would aid in identifying genes involved in NSC proliferation or self-renewal, we identified genes expressed in multiple CNS germinal zones and non-neural stem cell populations (Terskikh et al., 2001; Easterday et al., 2003). Postsynaptic density-95/Discs large/zona occludens-1 (PDZ)-binding kinase/T-LAK (lymphokine-activated killer T cell) cell-originating protein kinase (PBK/TOPK) was one transcript found to be consistently elevated in all progenitor cell populations examined consistent with a role in progenitor self-renewal.

$\mathrm{PBK} / \mathrm{TOPK}$ was not previously known to be involved in any facet of CNS development, but work in non-neural cells suggested that it was expressed in a variety of specialized, proliferative cell types: PBK/TOPK expression was detected in male germ line progenitor cells, activated T-cells, and a variety of lymphomas and leukemias. However, it was absent in WiDr and HT-29 colon cancer cells, indicating that it was not ubiquitously expressed in cycling cells (Abe et al., 2000; Simons-Evelyn et al., 2001; Zhao et al., 2001). Previous work also suggested that PBK/ 
TOPK was a member of the mitogen-activated protein kinase (MAPK) kinase (MAPKK) family (Abe et al., 2000; Gaudet et al., 2000; Matsumoto et al., 2004). Activated PBK/TOPK phosphorylated P38 MAPK but not JNK (c-Jun N-terminal protein kinase) MAPK or ERK (extracellular signal-regulated kinase) MAPK in vitro. Furthermore, activation of PBK/TOPK required phosphorylation by both the M-phase kinase complex cyclinB/cyclindependent kinase 1 (CDK1) and another unknown kinase, possibly RafC or RafA (Gaudet et al., 2000; Yuryev and Wennogle, 2003). These findings suggested that PBK/TOPK may play an important role in linking extracellular signals to an intracellular state, possibly allowing extracellular influence on the cell-cyclerelated processes of proliferation or differentiation. Here, this was supported by an initial informatics-based annotation that suggested a role for PBK/TOPK in M-phase in neural cells. Therefore, we examined phosphorylation of PBK/TOPK and P38 MAPK and the impact of P38 inhibition in cycling neuronal progenitors in vitro, which provided evidence that this pathway is involved in progenitor proliferation and self-renewal. We then demonstrated PBK/TOPK expression in specific progenitor cells in vivo, showing by ablation and lineage mapping that $\mathrm{PBK} /$ TOPK is a novel marker for transiently amplifying progenitor cells likely to be involved in the regulation of their self-renewal.

\section{Materials and Methods}

In situ hybridization. In situ hybridization was performed as described previously (Geschwind et al., 2001). Probes from an antisense $384 \mathrm{bp}$ fragment (GenBank accession number CA782113) and full-length PBK/ TOPK had identical expression patterns. For all in situ hybridizations, sense RNA controls showed no labeling above background.

Analysis of microarray data. Data were downloaded from National Institute of Neurological Disorders and Stroke (NINDS)/National Institute of Mental Health (NIMH) database (http://arrayconsortium.tgen.org). This set included 85 gliomas from 79 patients hybridized onto Affymetrix (Santa Clara, CA) HG133A and B arrays (Freije et al., 2004). Arrays were normalized with dCHIP (www.dchip.org), and expression values were calculated (Li and Wong, 2001). We filtered for genes with a coefficient of variation $>0.8$ to identify genes that varied significantly across samples. After filtering, there were 2217 probe sets representing 1874 highly variable genes, including PBK/TOPK. Pearson's correlation was performed to identify genes with an expression that covaried with PBK/TOPK at a highly significant level across the samples. DAVID (database for annotation, visualization, and integrated discovery) was used to classify correlated and anticorrelated genes into level 5 biological processes gene ontologies (Dennis et al., 2003). Expression Analysis Systematic Explorer (EASE) was used to test for statistical overrepresentation of categories relative to a background of all 1874 analyzed genes (Hosack et al., 2003). Results are similar if less filtered or unfiltered gene sets are used or if either whole array or whole genome is used for background comparison in EASE analysis.

Phylogenic analysis. Complete PBK/TOPK sequence for Homo sapiens and Mus musculus have been reported previously (Abe et al., 2000; Gaudet et al., 2000; Zhao et al., 2001). To identify key functional domains, we searched expressed sequence tag libraries with the National Center for Biotechnology Information Basic Local Alignment Search Tool (BLAST) and draft genome sequences with University of California, Santa Cruz Blat for PBK/TOPK sequence in all available vertebrate species. From these sequences, we were able to construct complete putative homologs for PBK/TOPK in Rattus norvegicus, Xenopus laevis, Gallus gallus, Danio rerio, Oncorhynchus mykiss, Canis familiarus, Tetraodon negroviridis, and nearly complete sequences for Pan troglodytes and Bos taurus using the DNASTAR Seqman software. We aligned these sequences with clustalW, implemented on DNASTAR Megalign software.

Culture of cerebellar granule cell precursors. Cerebella were harvested from postnatal day 6 (P6) to P8 CD1 mouse pups and digested in Papain with DNase and dissociated in PBS BSA with fire-polished pipettes fol- lowed by a cell strainer. Granule cell precursors were then separated on a $35 / 65 \%$ Percoll step gradient at $1500 \mathrm{~g}$ for $12 \mathrm{~min}$ as described previously (Wechsler-Reya and Scott, 1999). Cells were plated at $250 \mathrm{~K}$ cells/well onto poly-L-lysine-coated glass coverslips in 24-well plates in $330 \mu \mathrm{l}$ of Neurobasal media containing 2\% B27 supplement, 1 mM sodium pyruvate, $2 \mathrm{~mm}$ glutamine, and $1 \%$ penicillin/streptomycin, supplemented with $2.5 \mu \mathrm{g} / \mathrm{ml}$ mouse recombinant Sonic Hedge Hog (SHH) (461-SH025; R \& D Systems, Minneapolis, MN) as noted in our study.

Flow cytometry for cell cycle. Staining was as described previously (Krishan, 1975). Briefly, cells were lysed in a hypotonic buffer with Triton $\mathrm{X}-100$, RNase, and propidium iodide. DNA content of $>13,000$ nuclei was measured using cellquest software and a Facscaliber cytometer from Becton Dickinson (Mountain View, CA), and data were analyzed with ModFit 3.1 with service pack 2 for Macintosh to determine percentages of cells in the various phases of the cell cycle. All CV and RCS values were below five.

Preparation and specificity of anti-PBK/TOPK antibodies. The phosphospecific (Thr9) and total PBK/TOPK antibodies were produced by immunizing New Zealand White rabbits with synthetic peptides. The following peptides, coupled to keyhole limpet hemocyanin, were used: Thr9(P) (NFKT*PSKLSEKC) and total PBK/TOPK (CTNEDPKDRPSAAHIVE). Immunoglobulin was purified using protein A-Sepharose. To ensure phosphospecificity of the phospho-PBK/TOPK (Thr9) antibody, antibodies reactive with the nonphosphopeptide were removed by adsorption to a nonphosphopeptide affinity column. Antibodies that flowed through this column were passed over a column of immobilized phosphopeptide; after the column was washed, antibodies were eluted at low $\mathrm{pH}$ and dialyzed. For total PBK/TOPK, protein A-Sepharose purified antibodies reactive with the immunogenic peptide column were eluted and dialyzed. Analysis of the phosphospecificity of the resulting phospho-Thr9 antibody and phospho-independence of the resulting total PBK/TOPK antibody was performed by immunoblotting against whole-cell extracts from control and nocodazole-blocked ME-180 cells and recombinant activated glutathione $S$-transferase (GST)-PBK/TOPK or the protein dephosphorylated in vitro with $\lambda$ phosphatase (catalog \#P0753; New England Biolabs, Beverly, MA). The phosphoindependence of the total PBK/TOPK antibody was further established by comparing whole-cell extracts from NIH-3T3 and PC12 cells that were treated with the Ser/Thr phosphatase inhibitor calyculin A (catalog \#9902; Cell Signaling Technology, Beverly, MA) to extracts that were subjected to in vitro dephosphorylation with $\lambda$ protein phosphatase.

Animals. Transgenic mice were created and treated as described previously (Bush et al., 1999; Imura et al., 2003; Garcia et al., 2004). All animal protocols were approved by the University of California at Los Angeles animal research committee.

Immunohistochemistry. P7, P12, P14, P21 CD1, and adult CD1, C57BL/6, and transgenic mice were perfused transcardially with ice-cold PBS followed by ice-cold 4\% paraformaldehyde in PBS, pH 7.4. Brains were removed, fixed in $4 \%$ paraformaldehyde overnight, sunk in $20 \%$ sucrose PBS, frozen in 4-methyl-butane, and stored at $-80^{\circ} \mathrm{C}$ until use. Forty micrometer sections were cut on a cryostat and stored in PBS $0.1 \%$ azide at $4^{\circ} \mathrm{C}$ until use. Free-floating sections were incubated overnight in 24 -well plates on a rotator at room temperature in the presence of $0.1 \%$ azide, $0.25 \%$ Triton X-100, and 5\% normal goat serum in $500 \mu \mathrm{lPBS}$ and primary antibody at the following concentrations: anti-PBK/TOPK serum (1:500) (Gaudet et al., 2000), anti-PBK monoclonal (1:100; BD Transducin 612170), anti- $\beta$ III tubulin (Tuj1) (1:1000; MMS-435P; Covance, Princeton, NJ), anti-Mash1 (1:20; 556604; BD Biosciences), antiglutamate-aspartate transporter (GLAST; 1:5000; AB1782; Chemicon, Temecula, CA), anti-doublecortin (Dcx) (1:500; AB5910; Chemicon), anti-proliferating cell nuclear antigen (PCNA; 1:10000; M0879; DakoCytomation, Carpinteria, CA), anti-bromodeoxyuridine (BrdU; rabbit polyclonal; Upstate Biotechnology, Lake Placid, NY), antiminichromosome maintenance-deficient 2 (MCM2; sc-9839; Santa Cruz Biotechnology, Santa Cruz, CA) and anti-NG2 (rabbit polyclonal; Chemicon). For BrdU and PCNA, antigens were retrieved by incubating sections for $1 \mathrm{~h}$ at $65^{\circ} \mathrm{C}$ in $50 \%$ formamide, $2 \times$ SSX, and for $30 \mathrm{~min}$ in $2.0 \mathrm{~N} \mathrm{HCl}$ at $37^{\circ} \mathrm{C}$. Secondary antibodies were diluted 1:1000 and included cyanine 2 (Cy2)-, Cy3-, and Cy5-conjugated antibodies (Jackson 
ImmunoResearch, West Grove, PA) and Alexa 350-, 488-, 568-, and 594-conjugated antibodies (Invitrogen, San Diego, CA). For PBK/TOPK monoclonal antibody, Tyramide Signal Amplification (PerkinElmer Life Sciences, Emeryville, CA) was used occasionally to enhance signal. In all cases, no primary controls yielded no labeling, except in P7 animals, anti-mouse IgG Alexa 488 apparently labels some cells with a glial morphology. Where necessary, subtype-specific antibodies were used to avoid this confound.

Nuclei were counterstained with DAPI-containing mounting media (Vector Laboratories, Burlingame, CA) or with Topro-3-iodide (Invitrogen), a nuclear stain fluorescing in the far red range ( $650 \mathrm{~nm})$, by exposing tissue sections for $5 \mathrm{~min}$ to a $20 \mu \mathrm{M}$ solution in PBS.

Immunocytochemistry. Coverslips were harvested and fixed in $4 \%$ paraformaldehyde, washed in PBS, and blocked for $30 \mathrm{~min}$ in 5\% NGS $0.25 \%$ Triton X-100, and PBS. Cells were then exposed to primary overnight at room temperature at the following concentrations: anti-PBK/ TOPK, 1:500 (serum) or 1:100 (monoclonal); neuronal-specific nuclear protein (NeuN), 1:250 (Chemicon MAB377); PCNA, 1:5000; doublecortin, 1:500; cyclinB, 1:500 (4125; Cell Signaling Technology); phosphoP38 monoclonal, 1:100 (9216; Cell Signaling Technology); phospho-P38 polyclonal, 1:500 (9211; Cell Signaling Technology). Secondaries and counterstaining were as above.

Microscopy. All fluorescent images were acquired on either a Leica (Heidelberg, Germany) TCS-SP MP confocal and multiphoton inverted microscope and a two-photon laser setup (Spectra-Physics, Fremont, CA) or Zeiss (Thornwood, NY) LSM 510 META confocal microscope using lasers and filters appropriate for the fluorophores, and pseudocolored images were overlayed with Zeiss software or Adobe Photoshop (Adobe Systems, Santa Clara, CA). Far-red wavelengths were most often pseudocolored blue. To confirm colocalization of antibodies, stacks of $<1-\mu$ M-thick high-power confocal images were acquired and examined both as three-dimensional reconstructions and as animations moving through the Z plane with Zeiss LSM Image Browser.

Cell counts. For immunocytochemistry, all cells in 10 random $40 \times$ fields were counted. For the stem cell ablation experiments, we used a stereo investigator to count all PBK/TOPK cells in the subependymal zone (SEZ) ventral to the anterior horn at the level of the anterior commissure bilaterally in three replicate animals. $t$ tests were performed in Microsoft Excel (Microsoft, Redmond, CA). Colocalization studies were performed as above in two to four animals. Percentages are given as mean \pm SEM.

\section{Results}

\section{$\mathrm{PBK} / \mathrm{TOPK}$ transcript is expressed exclusively in neurogenic} regions in embryonic and adult CNS

Previous array studies demonstrated that PBK/TOPK was expressed by a wide variety of stem and progenitor populations in vitro, consistent with a role in stem/progenitor cell proliferation (Geschwind et al., 2001; Terskikh et al., 2001; Easterday et al., 2003). Here, we verified continued expression of PBK/TOPK in vivo, in prenatal and postnatal regions of neurogenesis, including the forebrain germinal zone (Fig. $1 A$ ), developing hippocampus and dentate gyrus (Fig. $1 B$ ), and rostral migratory stream (RMS); (Fig. 1C,D). Especially striking was the expression in the external granular cell layer (EGL) region of the cerebellum in the P7 animal (Fig. 1C). At this age, this structure is populated strictly by granular cell precursors, suggesting that PBK/TOPK is expressed by these neuronal progenitors in addition to the subventricular zone (SVZ), RMS, and hippocampal progenitors.

\section{PBK/TOPK is implicated in neural cell-cycle progression}

Previous literature suggested a role for PBK/TOPK in the cellcycle of non-neural cell types (Gaudet et al., 2000). We were curious whether this was the case in neural cells as well. To examine this hypothesis, we initially applied a bioinformatics-based functional annotation of PBK/TOPK in neural cells. This approach was based on the observation that genes that are involved

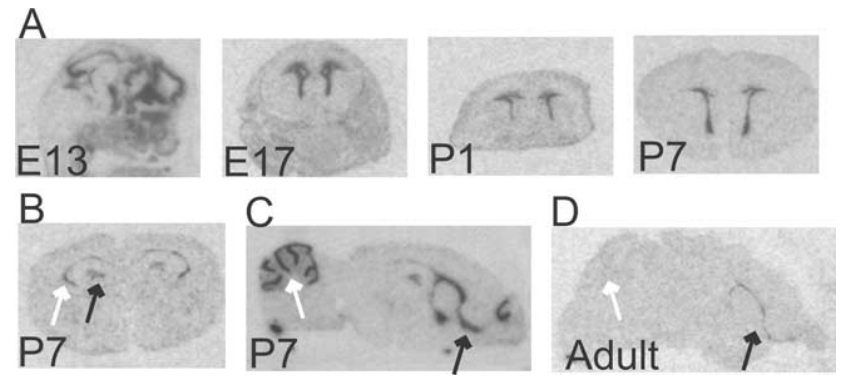

Figure 1. PBK/TOPK $m R N A$ is specifically expressed in all germinal zones throughout neural development. $\boldsymbol{A}-\boldsymbol{D}$, Autoradiographic films of in situ hybridization with $S^{35}$-labeled PBK/TOPK antisense RNA in regions in which stem and progenitor cells are found. $A$, PBK/TOPK is expressed in the forebrain germinal zones at embryonic day 13 (E13) (sagittal, whole head), E17 (coronal, whole head), P1 (coronal), and P7 (coronal). B, C, PBK/TOPK is also expressed in the dentate gyrus (black arrow) and the posterior lateral ventricle (white arrow) at P7 (coronal) (B) and in the developing cerebellum (white arrow) and the RMS (black arrows) in sagittal sections at P7 (C). D, Expression continues in the subventricular zone and RMS of the sagittal adult brain (black arrow) but not the cerebellum (white arrow).

in the same biological process are often tightly coregulated (Eisen et al., 1998; Ren et al., 2000; Miki et al., 2001). If we identified genes falling into specific categories of biological processes that were highly coregulated with PBK/TOPK, this would generate testable hypotheses regarding PBK/TOPK function in neural tissue. In addition, this type of informatic screen should be of interest as a method to rapidly generate hypotheses regarding the function of unstudied or novel genes, as well as infer function for previously studied genes in new contexts.

To perform this analysis, we needed a large neural dataset $(n=$ 30 or more) with variable PBK/TOPK expression, and thus we capitalized on array data from neural tumors available in the NINDS/NIMH microarray database. Although brain tumors are not normal progenitors, they are proliferative neural tissue, and data from several sources have demonstrated recently that some tumors, including gliomas, contain a multipotent tumor stem cell from which they derive (Ignatova et al., 2002; Hemmati et al., 2003; Singh et al., 2003; Galli et al., 2004). We reasoned that using this rich neural tumor dataset to derive hypotheses about the function of a neural stem cell gene would be appropriate, provided that these hypotheses were then tested in the noncancerous, primary neural cells of interest. Furthermore, it was one of only a few datasets with enough distinct samples to permit such an analysis with sufficient precision. We therefore focused on a large-scale study of gliomas in this database (Freije et al., 2004). Although PBK/TOPK was detected in 79 of the 85 gliomas in this set, it showed a high degree of variability, ranging $>50$-fold, which made this data set amenable to assessing gene coregulation.

We created a gene coregulation matrix and observed that PBK/TOPK was strikingly correlated with a large number of genes involved in the cell-cycle machinery, including ki-67, aurora kinase B, and cyclin B1 (see Materials and Methods). To understand the level of significance of this finding in an unbiased manner, we performed statistical analysis of gene ontology categories using EASE (Hosack et al., 2003). This revealed that in the group of genes most correlated to PBK/TOPK, there is a highly significant overrepresentation of genes involved in the cell cycle (EASE statistic; $p<10 \mathrm{e}-15$ ), especially M-phase genes (EASE statistic; $p<10 \mathrm{e}-12$ ) (supplemental Fig. $1 A$, available at www. jneurosci.org as supplemental material). These data in neural tissues was parallel to data showing cell-cycle regulation of PBK/ TOPK expression in synchronized HeLa cells (Whitfield et al., 2002; Matsumoto et al., 2004). This specific pattern of correlation 
suggested that PBK/TOPK may play a fundamental role in the cell cycle in neural progenitor cells and tumors that derive from them, especially in the $\mathrm{M}$ phase of the cell cycle. In addition, an examination of phylogenetic conservation of the PBK/TOPK protein sequence across multiple vertebrate species demonstrated conservation of the cyclinB/CDK1 phosphorylation site and kinase domains, whereas the eponymous PDZ-binding motif is found only in primates (supplemental Fig. $1 C$, available at www.jneurosci.org as supplemental material). Protein domains that are conserved across a variety of species may be important to the function of a protein, so we chose to focus our initial in vitro analysis on PBK/TOPK regulation in the cell cycle in neural cells and this site in particular (see below and Fig. 3).

\section{$\mathrm{PBK} / \mathrm{TOPK}$ is expressed by proliferating cerebellar granule} cell precursors in vitro

For in vitro $\mathrm{PBK} / \mathrm{TOPK}$ studies, we isolated primary cerebellar granule cell precursors (CGPs) from the EGL of the cerebellum, because PBK/TOPK was highly expressed in this region (Fig. 1C, white arrow), and these cells represent a relatively homogeneous neuronal progenitor pool that would simplify analysis. Previous work has shown that CGPs will proliferate in response to the mitogen SHH (Wechsler-Reya and Scott, 1999). We compared the expression of PCNA, PBK/TOPK protein, NeuN, and Dcx in CGPs cultured with or without mitogenic stimulus. PBK/TOPK expression overlapped highly with PCNA $(98.31 \pm 1.38 \% ; n=$ 138), and expression of both PCNA and PBK/TOPK decreased dramatically in the absence of mitogen (Fig. $2 A$ ), in which case CGPs developed elaborate Dcx-positive process (data not shown). In contrast, relative expression of NeuN, a marker of more mature neurons, increased in the absence of $\mathrm{SHH}$, and PBK/TOPK expression did not overlap with NeuN (Fig. $2 B$ ).

\section{PBK/TOPK phosphorylation on cyclinB site is}

cell-cycle regulated

Having confirmed that PBK/TOPK was present in neuronal progenitor cells in vitro, we examined whether PBK/TOPK may be activated by phosphorylation in these cells. In non-neural cells, $\mathrm{PBK} / \mathrm{TOPK}$ appears to require cyclinB/CDK1 phosphorylation for activation (Gaudet et al., 2000). Therefore, we produced an antibody against a phosphorylated form of the cyclinB/CDK1 target site (supplemental Fig. $1 C$, available at www.jneurosci.org as supplemental material) as a method of gauging activation of PBK/TOPK. We initially tested this antibody with cell lines that express PBK/TOPK. This antibody recognized a PBK/TOPKsized band, observed only in cells blocked in mitosis with nocodazole (Fig. 3A). This antibody also detected recombinant, activated GST-PBK/TOPK, and the signal decreased dramatically when recombinant GST-PBK/TOPK was phosphatase-treated (Fig. 3B), demonstrating specificity of the protein for the phosphorylated form of PBK/TOPK.

We then examined the phosphorylation of PBK/TOPK across the cell cycle. Flow cytometry revealed that phospho-PBK/ TOPK-positive cells all had high DNA content, indicating that they had likely finished the $S$ phase and were in either the $\mathrm{G} 2$ or M phase of the cell cycle (Fig. 3C). To determine whether the expression was in the G2 or M phase, we conducted immunocytochemistry on N2a neuroblastoma and P19 embryonic carcinoma cells. In both lines, phospho-PBK/TOPK was only detected in cells with condensed chromatin indicative of M-phase cells. Furthermore, it was clearly detected throughout all stages of mitosis, outlining condensed chromosomes, but its expression decreased abruptly and dramatically in telophase, and by late telophase,

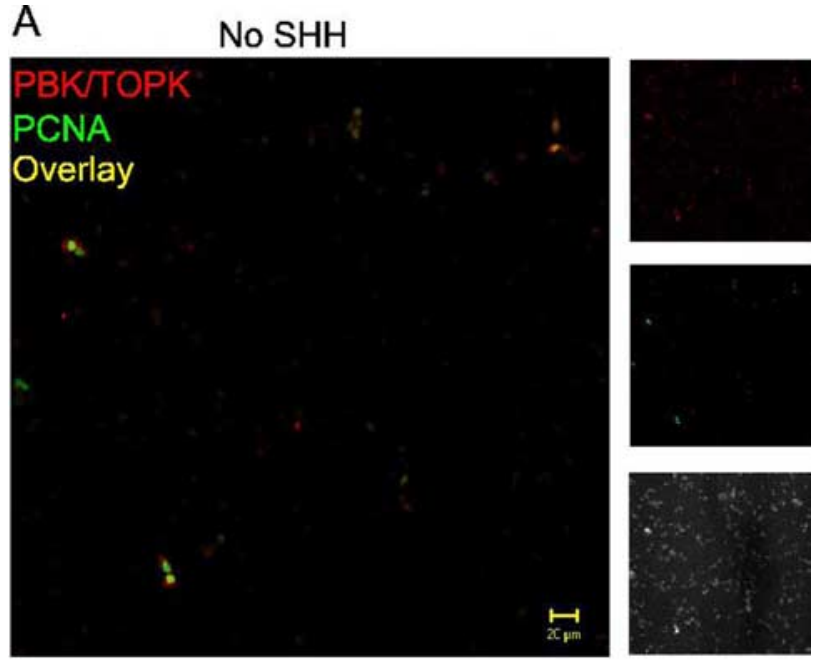

$72 \mathrm{H} \mathrm{SHH}$

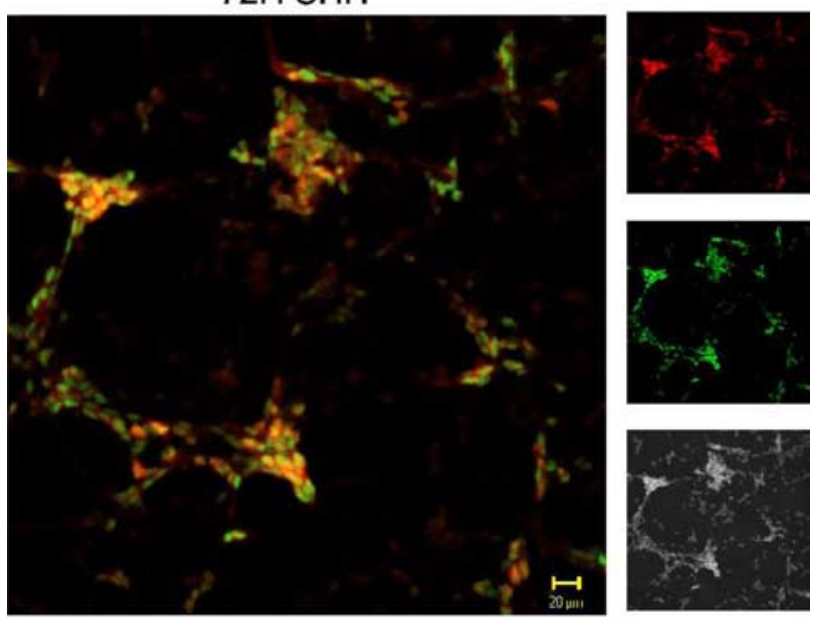

\section{B SHH drives proliferation and PBK/TOPK expression}

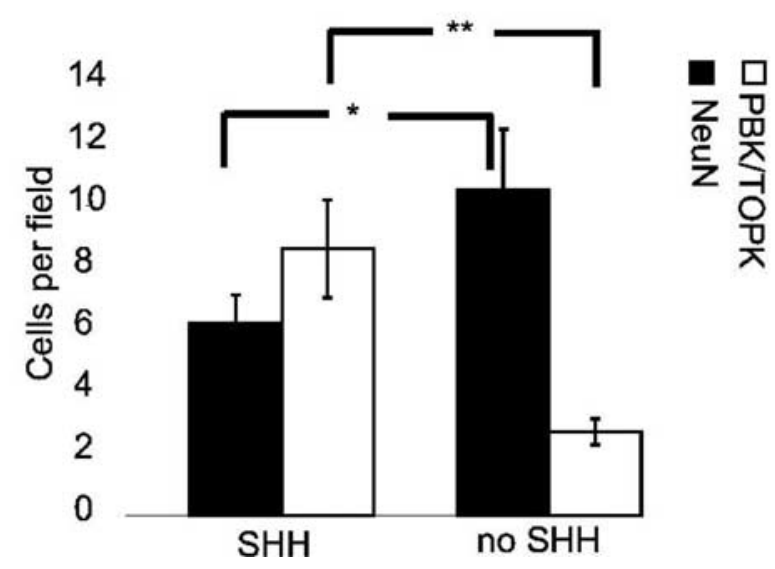

Figure 2. PBK/TOPK is expressed in proliferating cerebellar granule cell precursors in vitro. $A$, Consistent with what is seen in vivo in the cerebellum, $72 \mathrm{~h}$ after dissection (72H), CGPs treated with mitogen SHH form proliferative clumps of PBK/TOPK (red) and PCNA (green) doublepositive cells while the untreated cells stop proliferating and differentiate. Background signal is included in gray to show total cell population. $\boldsymbol{B}$, Quantification of this effect reveals that CGPs in cultures treated with mitogen maintain expression of PBK/TOPK. Untreated cultures have proportionally more cells that express the neuronal maturation marker NeuN. 
A

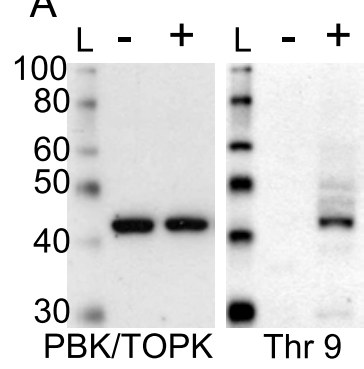

B

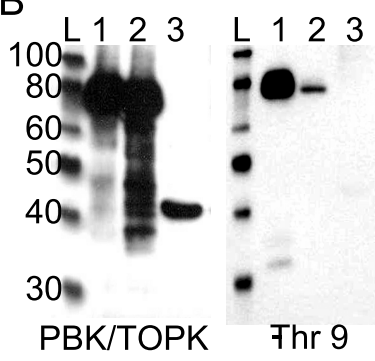

C

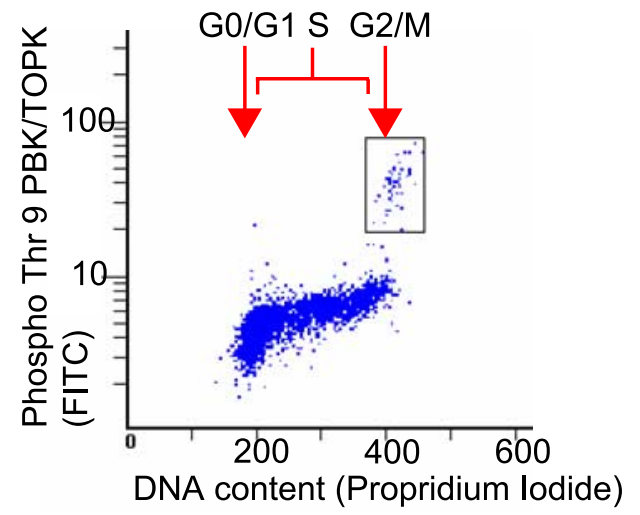

D
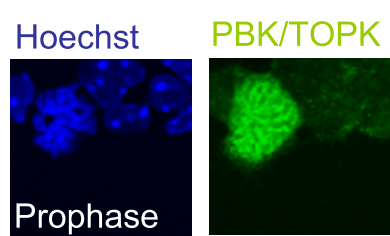

Phospho
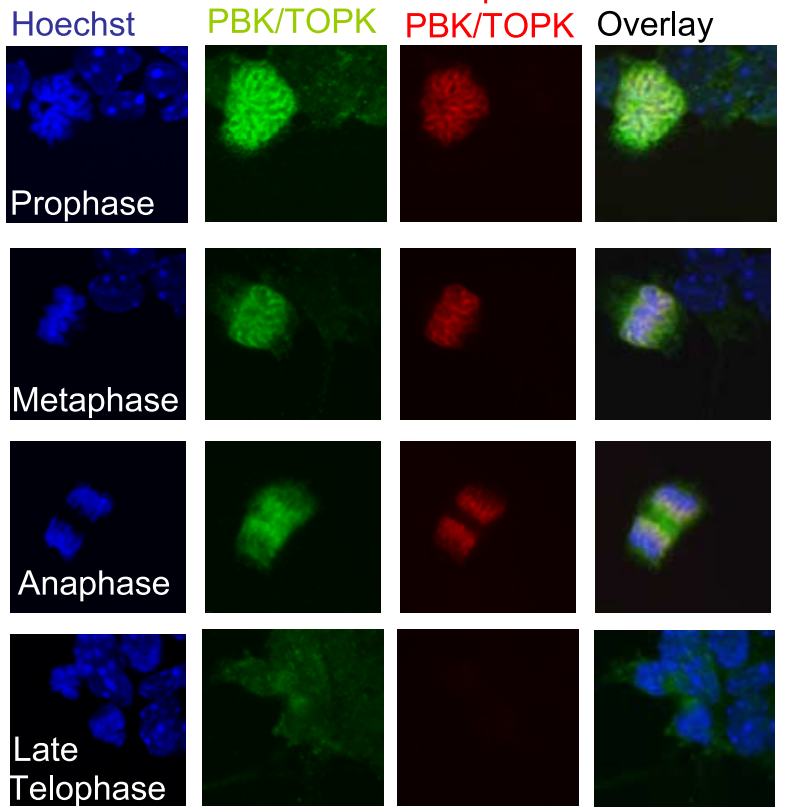

E
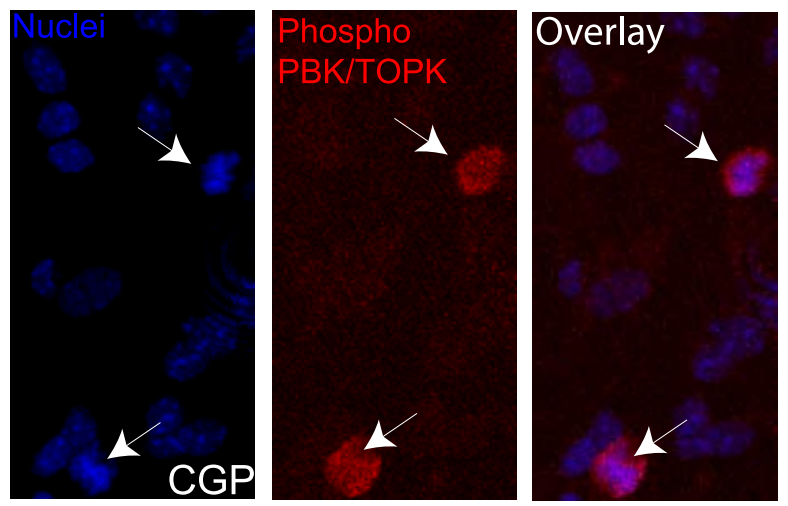

PBK/TOPK protein itself seemed to disappear (Fig. 3D). Finally, we confirmed this finding in primary cells (CGPs) (Fig. 3E). This suggests that PBK/TOPK is not only expressed in these cells but also phosphorylated and activated.

The PBK/TOPK target P38 MAPK is also phosphorylated in a cell-cycle-dependant manner in neural progenitor cells

Next, we wished to examine whether the PBK/TOPK target P38 MAPK is also phosphorylated in neural progenitors, because in non-neural cells, PBK/TOPK phosphorylates P38 MAPK, activating it (Abe et al., 2000). Because MAPK pathways are highly conserved, we examined the phosphorylation of P38 MAPK in relation to proliferation and the cell cycle in primary CGP cells. We found that differentiation induced by mitogen withdrawal significantly reduced the number of cells positive for phosphoP38 (paired $t$ test; $p<0.01$ ). Furthermore, strong phospho-P38 was only detected in cyclinB-positive CGPs (Fig. 4A). CyclinB is the $\mathrm{G} 2 / \mathrm{M}$ phase-expressed cyclin that directs $\mathrm{CDK} 1$ to phosphorylate PBK/TOPK. Coexpression of cyclinB and phospho-P38 suggested that $\mathrm{P} 38$ is selectively activated in these cells in the G2/M phases of the cell cycle. Close examination of DNA in phospho-P38-positive cells revealed that they show the condensed chromatin characteristic of mitotic cells, suggesting activation in a cell-cycle-dependant manner. We performed double labeling with phospho-PBK/TOPK and phospho-P38 MAPK. Strikingly, all phospho-PBK/TOPK-positive cells were mitotic and phospho-P38 positive (Fig. $4 \mathrm{~B}$ ). Thus, the PBK/TOPK target P38 appears to be phosphorylated specifically during mitosis in proliferating CGPs, consistent with other reports of mitotically phosphorylated P38 in neuronal progenitors in other germinal zones (Campos et al., 2002). The complete overlap of P38 phosphorylation with PBK/TOPK phosphorylation in CGPs was also seen in N2a and P19 cell lines (data not shown).

\section{P38 MAPK inhibition decreases proliferation of} primary progenitors

The studies above suggested that the P38 MAPK pathway was being activated through PBK/TOPK in a cell-cycle-specific manner. We next wished to determine whether this activation had any relevance to the proliferation of primary progenitor cells. We found that treatment of cultured primary CGP with the specific

Figure 3. PBK/TOPK is phosphorylated exclusively during mitosis. $A$, An antibody raised against phosphorylated cyclinB/cdk1 site at threonine 9 (Thr 9) on PBK/TOPK only has signal in ME-180 cells treated with nocodazole, which blocks cells in mitosis (right blot). Probing with total PBK/TOPK antibody reveals equal amounts of PBK/TOPK protein in treated and untreated conditions (left blot). L, Molecular weight marker; + , treated; - , untreated. B, PBK/TOPK (left blot) and phospho-PBK/TOPK (right blot) antibodies recognize a recombinant activated GSTPBK/TOPK. Phospho-PBK/TOPK signal decreases with phosphatase treatment. L, Molecular weight marker; 1, ProQinase active GST-PBK (80 kDa); 2 , GST-PBK after $\lambda$ phosphatase treatment; 3, ME-180 (untreated) whole-cell lysate. C, Flow cytometric analysis of untreated Jurkat cells, using phospho-PBK/TOPK antibody labeled with FITC ( $y$-axis) versus DNA content measured by propidium iodide ( $x$-axis), which can be used to measure the position of a cell in the cell cycle. The boxed population indicates that phospho-PBK/TOPK-positive cells have 4N DNA content indicative of either $\mathrm{G} 2$ or M phase cells. D, A 100 X immunocytochemistry on N2A cells shows that phospho-PBK/TOPK is expressed specifically throughout the $M$ phase, but expression of PBK/TOPK (green) and phospho-PBK/TOPK (red) decreases dramatically in late telophase. Notice that nonmitotic adjacent cells are phospho-PBK/TOPK negative. E, A 20 $\times$ immunocytochemistry, as with N2A in primary neuronal precursors (CGPs), reveals that phosphoPBK/TOPK (red) is detected only in cells undergoing mitosis as indicated by their condensed chromatin (arrowheads). 

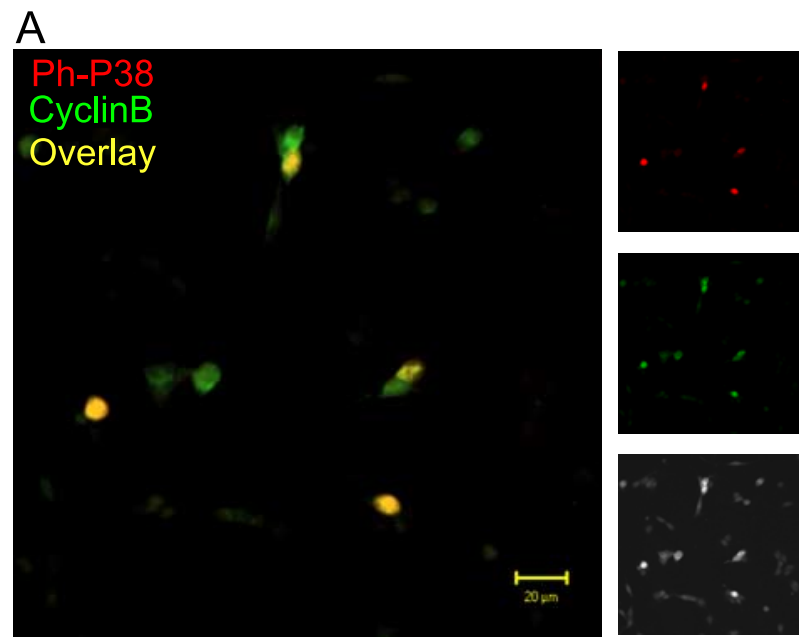

\section{B}

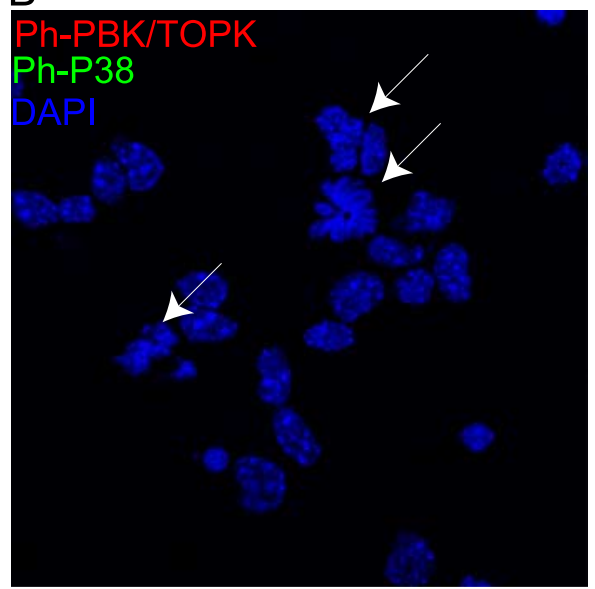

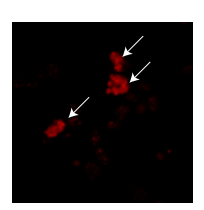
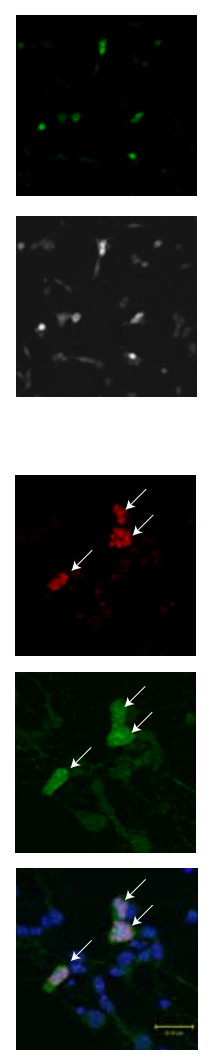

C

\section{P38 inhibition decreases mitogen induced cell cycling in CGPs.}

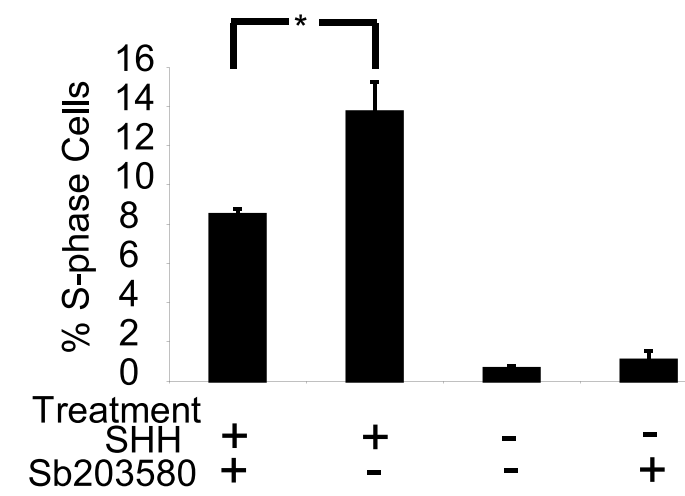

Figure 4. $\mathrm{PBK} / \mathrm{TOPK}$ target P38 MAPK is also phosphorylated at mitosis in primary neuronal precursors and is required for normal proliferation. $A$, Strong P38 MAPK phosphorylation (red) occurs only in G2/M, cyclinB-positive primary CGPs (green), suggesting that P38 is activated primarily in the G2/M phase in these cells. B, Strong phospho-P38-positive (green) CGPs are always phospho-PBK/TOPK positive (red) and vice versa. Furthermore, they have the condensed chromatin of mitotic cells (arrowheads), suggesting that PBK/TOPK activates phospho-P38 at mitosis in these cells. C, The P38 MAPK-specific inhibitor SB203580 reduces a fraction of S-phase cells in proliferating CGP. Harvested CGPs were cultured with or without mitogen for $48 \mathrm{~h}$, and $50 \mu \mathrm{m}$ SB203580, the specific P38 MAPK inhibitor, was added. After $24 \mathrm{~h}$, cells were harvested and subjected to cell-cycle analysis via flow cytometric measurement of DNA content and immunocytochemistry. D, Cell counts of PBK/TOPK and NeuN-positive cells reveal that SB203580 reduces PBK/TOPK-positive proliferating progenitor cells and total number of cells, without significantly impacting nonproliferative, differentiated NeuN-positive cells. Error bars represent SD.

P38 inhibitor 4-(4-fluorophenyl)-2-(4-methylsulfonylphenyl)5-(4-pyridyl)-1 H-imidazole (SB203580) (Gallagher et al., 1997) resulted in a dramatic decrease in the fraction of cells in the S-phase (Fig. 4C). Twenty-four hours of P38 inhibition caused a reduction in the number of the $\mathrm{PBK} / \mathrm{TOPK}$-positive cells (the proliferating, PCNA-positive cells). However, in the absence of mitogen treatment on the primary progenitors, P38 inhibition had no impact on cell number (Fig. 4D) in NeuN-positive differentiating cells, indicating that P38 inhibition was not killing cells in a nonspecific manner but specifically impacting the proliferating cells. To extend these findings to other primary progenitor populations in addition to the CGPs, we also exposed attached neural progenitors cultured from E12 mouse telencephalic germinal zones to varying doses of SB203580 in the presence of the mitogen basic fibroblast growth factor (bFGF). These cells also express PBK/TOPK and phosphorylate P38 in a cell-cycledependent manner (supplemental Fig. $2 \mathrm{~A}$, available at www. jneurosci.org as supplemental material) (data not shown). We saw a dose-dependant decrease in cell number after exposure to drug (supplemental Fig. $2 \mathrm{~B}$, available at www.jneurosci.org as supplemental material) and a decrease in cycling cells as assessed by flow cytometry. At long exposures or high doses, we also observed an accumulation of DNA-aneuploid cells, suggesting that those cells that did survive were not completing cell division properly (supplemental Fig. 2C, available at www.jneurosci.org as supplemental material).

\section{PBK/TOPK is not expressed by postmitotic neuroblasts or mature glia in vivo}

These in vitro data suggested a role for PBK/TOPK in neural progenitor and immortalized cell line cell-cycle progression and division. To examine whether such a role was consistent with in vivo expression data, we performed a battery of immunohistochemical analyses with several markers of proliferation, differentiation, and progenitor states. Two different antibodies to PBK/ TOPK in early postnatal and adult mice showed the same cytoplasmic and occasionally nuclear expression in the regions of ongoing neurogenesis: the subgranular layer of the dentate gyrus, the subependymal zone of the lateral ventricles, the rostral migratory stream in all ages, and the EGL of the early postnatal cerebellum, consistent with in situ hybridization results. Postnatal expression is summarized in Table 1 . Note that, in our experiments, we did not 
Table 1. Postnatal distribution of PBK/TOPK expression

\begin{tabular}{lllll}
\hline & P7-P8 & P12-P14 & P21 & Adult \\
\hline Cerebellum & + & + & & \\
$\quad$ External granule layer & +++ & + & & \\
$\quad$ White matter & ++ & & & \\
$\quad$ Cortex & & & & \\
$\quad$ Subcortical white matter & + & & & \\
Hippocampus & ++ & + & & \\
$\quad$ Subgranular layer & ++ & ++ & & \\
Lateral ventricles & & & + & + \\
$\quad$ Subventricular zone & ++ & ++ & + & ++ \\
$\quad$ Anterior subventricular zone & +++ & +++ & + & ++ \\
Rostral migratory stream & +++ & +++ & ++ & ++ \\
\hline
\end{tabular}

observe PBK/TOPK expression in the adult corpus callosum, fornix, or other white matter regions where mature oligodendrocytes are predominantly found and thus concluded that mature oligodendrocytes do not generally express PBK/TOPK.

We examined the expression of PBK/TOPK in depth in two regions of postnatal neurogenesis, the EGL and the SEZ/RMS, to identify what cell type expresses PBK/TOPK in vivo. For the first 2 weeks after birth, cerebellar granule neurons continue to be born from the EGL. The EGL contains a mitotic layer with PCNA-positive proliferating progenitors (EGLa), a premigratory layer with postmitotic immature neurons (EGLb), and the radially oriented processes of Bergmann glia (Migheli et al., 1999). Double-label immunohistochemistry of PBK/TOPK and Tuj1 or Dcx (data not shown), both markers of immature neurons, reveal clear expression of PBK/TOPK in the PCNA-positive mitotic (Fig. $5 B$ ) but not the premigratory (Fig. 5D) zones of the EGL. Not surprisingly, there was no PBK/TOPK expression in the cerebellum in the P21 or adult animal, when neurogenesis in the cerebellum is complete (data not shown). In the EGL, scaffolding for cell division and migration are provided by GLAST-positive Bergmann glia (Furuta et al., 1997), which are PBK/TOPK negative (Fig. 5C). This pattern of expression is consistent with a role in proliferation of neuronal progenitors in the cerebellum.

In adult animals, PBK/TOPK is expressed sporadically within the subgranular layer of the dentate gyrus and strongly within the subependymal zone of the lateral ventricle. Especially striking is the postnatal PBK/TOPK expression in the neurogenic SEZ and the full extent of the rostral migratory stream from the anterior lateral ventricle to the beginning of the olfactory bulb (Fig. 6B). This expression is seen in all ages examined but decreases in intensity from P7 to adulthood. Most PBK/TOPK-positive cells were also PCNA positive when examined at high magnification. To further assess PBK/TOPK expression within migratory immature neuroblasts in the SEZ and RMS, we performed double labeling with Tuj1 and Dcx. Dcx expression had perfect overlap with strongly positive Tuj1 cells, so only Dcx is shown here. PBK/ TOPK was strongly expressed in cells adjacent to, but not in, clusters of Dcx (Fig. 5E)-positive cells, consistent again with PBK/ TOPK being expressed in proliferating neuronal progenitors but not in postmitotic immature neurons. There were a small fraction of cells that may have been positive for Dcx/Tuj1 and dimly positive $\mathrm{PBK} / \mathrm{TOPK}$, perhaps representing a transition state or the minority of Tuj1-positive cells that are still proliferative.

Recent evidence strongly suggests that the primary stem cell of the adult central nervous system is GFAP positive (Doetsch et al., 1999b; Imura et al., 2003; Garcia et al., 2004). We performed double-label immunohistochemistry for GFAP and PBK/TOPK to assess potential coexpression. We did not observe any double- labeled cells in the adult subependymal zone (Fig. $5 F$ ), suggesting that if they did exist, they were rare.

\section{PBK/TOPK expression overlaps with markers of proliferation and progenitor cells}

To further examine the cellular context of PBK/TOPK expression, we performed double- and triple-label immunohistochemistry with neural progenitor cell markers and several markers of cell proliferation (Figs. 5B, 6B-E). After four injections of BrdU over $2 \mathrm{~d}$, all $\mathrm{PBK} / \mathrm{TOPK}$-positive cells were BrdU positive (Fig. $6 \mathrm{D})$. However, there were many BrdU-positive, but PBK/TOPKnegative cells. Most of these cells were Dcx positive. We surmised that the PBK/TOPK BrdU double-positive cells were currently proliferating population of cells, whereas the Dcx/BrdU-positive population represented primarily recently born neurons.

We tested this hypothesis in more detail, first, by colabeling with the PCNA antibody, which recognizes a subunit of the DNA-polymerase III complex involved in DNA synthesis during the S-Phase (Tsurimoto, 1999). Virtually all (94.7 $\pm 2.3 \% ; n=$ 387) of the cells expressing PBK/TOPK in all regions, and at all ages, also expressed PCNA, suggesting that PBK/TOPK was expressed in cycling cells (Figs. $5 B, 6 B$ ). However, not all of the PCNA-positive cells were $\mathrm{PBK} / \mathrm{TOPK}$ positive, suggesting that the vast majority $(94.3 \pm 1.9 \% ; n=392)$, but not all, cycling cells in this region expressed PBK/TOPK (Fig. 6C). Next, we examined whether PBK/TOPK was expressed by rapidly cycling cells, or slowly cycling cells, by assessing PBK/TOPK expression several weeks after BrdU injections. This typical experimental design is based on the observation that slower cycling cells retain BrdU, whereas rapidly cycling cells dilute the BrdU beyond detection. The MCM2 protein, which is expressed in the G1 phase, was used to determine whether any of the slowly cycling cells were reentering the cell cycle (Maslov et al., 2004). Four weeks after BrdU injection, we saw few BrdU-positive cells in the SEZ and did not see any BrdU/MCM2 double-positive cells, suggesting the BrdU-labeled cells were quiescent or postmitotic. There was no overlap between PBK/TOPK- and BrdU-positive cells, suggesting PBK/TOPK is not expressed in SEZ cells when they are not actively proliferative. There was, however, extensive overlap between MCM2 and PBK/TOPK, once again demonstrating that $\mathrm{PBK} / \mathrm{TOPK}$ is expressed in actively cycling cells (Fig. 6E).

To examine PBK/TOPK expression in putative neuronal progenitors outside the EGL, we studied its colocalization with the proneural basic helix-loop-helix transcription factor Mash1. Mash1 has recently been shown to specify neuronal and oligodendritic fate in the postnatal brain in vitro and in vivo (Parras et al., 2004), and Mash1 knock-out mice have morphological defects in the olfactory bulb (Guillemot, 1995; Murray et al., 2003; Parras et al., 2004). This suggests that Mash1 may play a role in olfactory bulb neurogenesis, which occurs throughout a mammal's lifetime, because neurons born in the subependymal zone of the anterior lateral ventricle and RMS migrate to the olfactory bulb (Luskin, 1993). Consistent with this, we observed Mash1 expression for the extent of the SEZ and RMS in the adult animal, as was recently reported by Parras et al. (2004). Strikingly, at least 95\% of Mash1-positive cells in adult SEZ/RMS (96.3 $\pm 1.0 \%$; $n=$ 207) were also clearly PBK/TOPK positive, suggesting that PBK/ TOPK is expressed in a significant proportion of neuronal progenitors destined for the olfactory bulb (Fig. 6F). Mash1 and $\mathrm{PBK} / \mathrm{TOPK}$ double-positive cells were seen in SEZ and RMS, but the PBK/TOPK-positive cells of the EGL of the cerebellum at P7 were clearly Mash1 negative (data not shown), demonstrating that not all neurogenic cells expressed Mash1, and not all PBK/ 

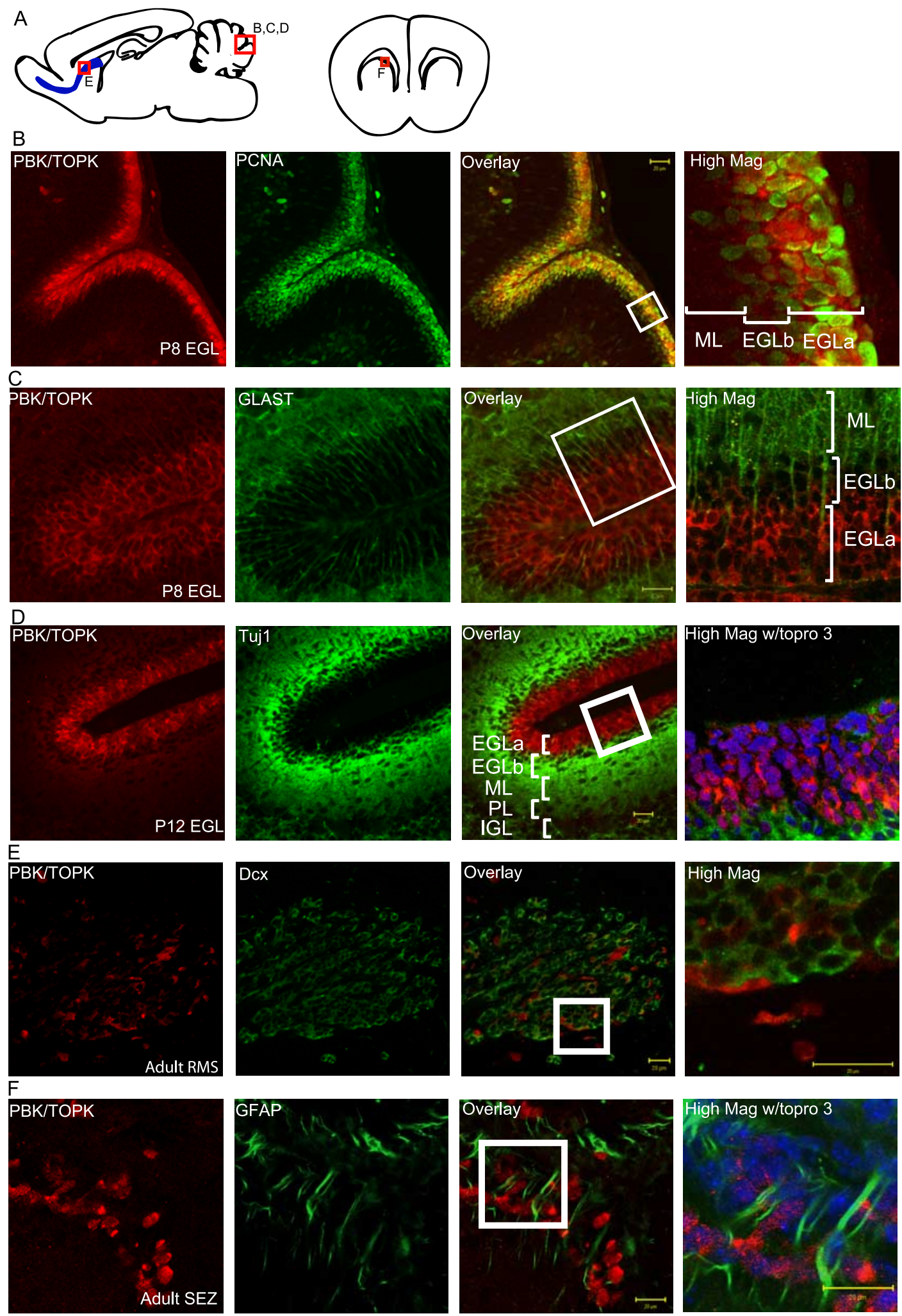

Figure 5. PBK/TOPK protein is not expressed in neurons or mature glia in the EGL or the SEZ and RMS. $\boldsymbol{A}$, Schematics of tissue slices showing locations of $\boldsymbol{B}-\boldsymbol{F}$ as red boxes. The RMS is in blue. $\boldsymbol{B}$, PBK/TOPK (red) is expressed in the cytoplasm of cells in the PCNA-positive (green) mitotic layer of P8 EGL. Right, A $100 \times$ magnification of the region similar to the box. Confocal reconstructions reveal that all PCNA-positive nuclei are surrounded by PBK/TOPK-positive cytoplasm. C, PBK/TOPK (red) is not expressed in GLAST (green)-positive Bergmann glia, the fibers of which provide scaffolding in P8 EGL. Right, 100× magnification of region in box. D, PBK/TOPK (red) is not expressed in Tuj1 (green)-positive immature granule cell neurons in P12 EGL. Right, A 100X magnification of the region similar to the box, with topro-3-iodide (blue) added to label nuclei. $E$, PBK/TOPK (red) does not generally overlap with immature migrating neurons expressing Dcx (green) in a postnatal RMS. Right, A 63× magnification of the box. F, PBK/TOPK (red) does not generally overlap with GFAP (green)-positive mature astrocytes in adult SEZ. Right, Magnification counterstained with topro-3-iodide (blue). Scale bars, 20 m. ML, Molecular layer; PL, Purkinje cell layer; IGL, internal granular layer. 

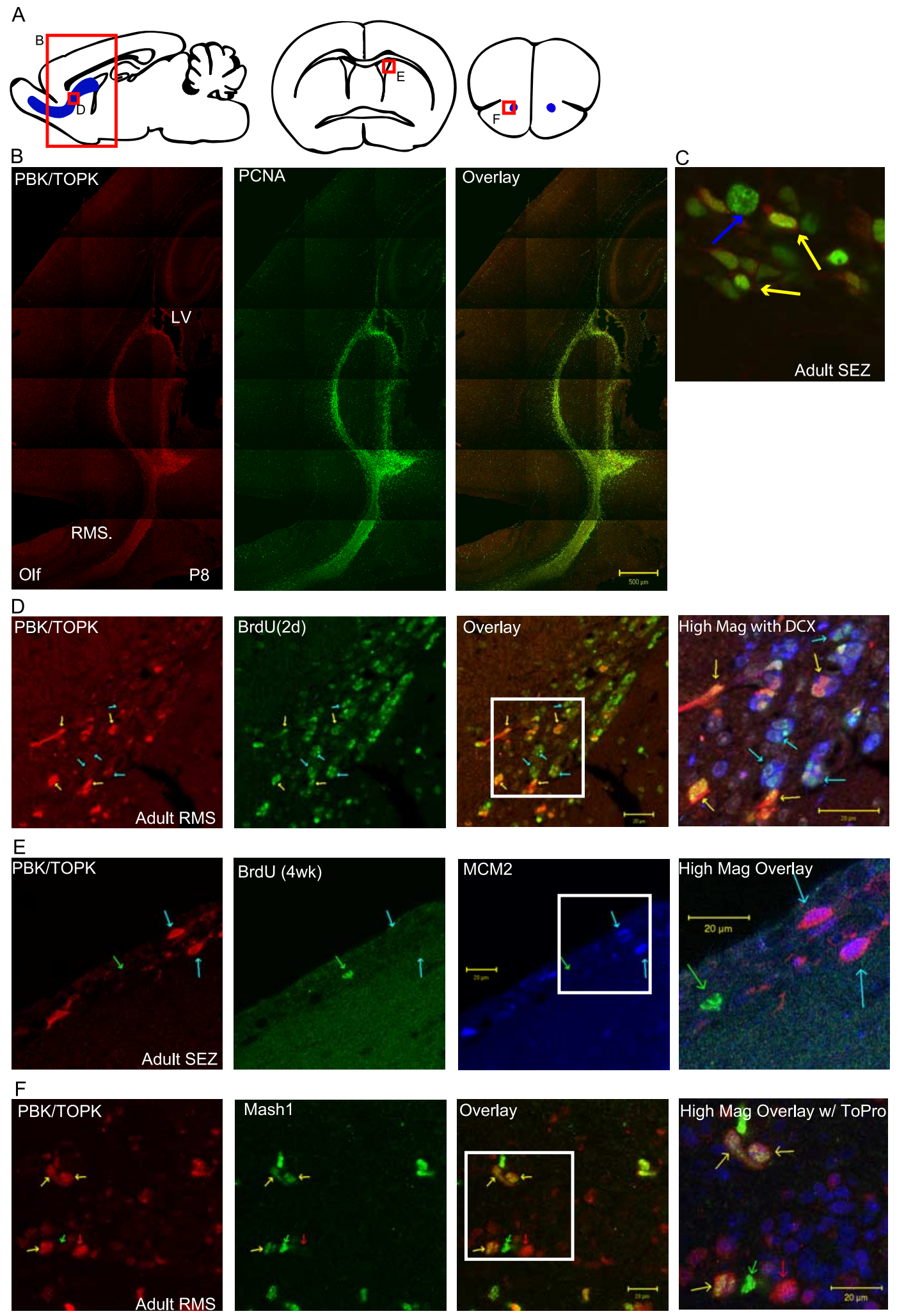

Figure 6. $\mathrm{PBK} / \mathrm{TOPK}$ is expressed exclusively in rapidly proliferating cells in the postnatal rodent brain. $\boldsymbol{A}$, Schematics of tissue slices showing locations of $\boldsymbol{B}-\boldsymbol{F}$ in red boxes. The RMS is in blue. $\boldsymbol{B}$, Montage of $1510 \times$ fields showing the front-third of a sagittally cut P8 brain. PBK/TOPK is expressed for the extent of the SEZ of the lateral ventricle and RMS around PCNA-positive nuclei. LV, Lateral ventricle; Olf, olfactory bulb. C, Most PBK/TOPK-positive cells have PCNA-positive nuclei: a 100 $\times$ section of adult SEZ showing PCNA single-labeled (blue arrow) and PCNA-PBK/TOPK double-labeled (yellow arrows) cells. $\boldsymbol{D}$, In the adult RMS after four BrdU pulses in $2 \mathrm{~d}$, all PBK/TOPK (red) cells have BrdU (green)-positive nuclei, showing recent birth or current proliferation (yellow arrows). Remaining BrdU-positive cells have Dcx (blue)-positive cytoplasm, a marker of immature neurons (blue arrows). Right, Magnification with Dcx included. $\boldsymbol{E}$, Four weeks after a BrdU injection, there is still extensive overlap (blue arrows) between proliferation marker MCM2 (blue) and PBK/TOPK (red) but no overlap with MCM2 or PBK/TOPK and BrdU (green) in what are presumably slower cycling or quiescent cells. Right, Magnification of boxed region. $\boldsymbol{F}$, There is extensive overlap between Mash1-positive (green) neuronal progenitor nuclei and PBK/TOPK (red) in adult RMS. Right, Magnification counterstained with topro-3-iodide: green arrow, MASH1 single-positive cell; red arrow, PBK/TOPK single-positive cell; yellow arrows, PBK/TOPK MASH1 double-positive cells.High Mag, High magnification. 
TOPK cells were Mash1 positive. However, more than three-fourths of PBK/ TOPK-positive cells were Mash1 positive in adult $\operatorname{SEZ}(81.0 \pm 2.6 \% ; n=243)$, showing that PBK/TOPK is highly enriched in these progenitors.

We also compared PBK/TOPK expression with the expression of the epidermal growth factor (EGF) receptor (EGFR) and the NG2 chondroitin sulfate proteoglycan. EGF promotes the proliferation of neural progenitors in vitro and in vivo, and EGFR-positive cells are thought to be sphere-forming C cells (Doetsch et al., 2002). NG2 has traditionally been thought of as marker of oligodendrocyte or glial progenitors. Recently, a subset of NG2positive cells in SEZ have also been identified as sphere forming, possibly C cells, but in contrast to EGFR, it is expressed in many regions beyond the neurogenic SEZ (Doetsch et al., 2002; Aguirre et al., 2004). Within the SEZ, $78.8 \%( \pm 8.0 \% ; n=115)$ of PBK/TOPK-positive cells were clearly EGFR positive, and $95.8 \%( \pm 2.4 \%$; $n=108)$ of EGFR-positive cells were clearly PBK/TOPK positive (supplemental Fig. 3B, available at www.jneurosci.org as supplemental material), showing that the $\mathrm{PBK} / \mathrm{TOPK}$-positive population is highly overlapping with the EGFR expressing, sphere-forming cell population of the SEZ. Also, some PBK/TOPK-positive cells in the SEZ expressed NG2 (supplemental Fig. 3C, available at www.jneurosci.org as supplemental material). However, NG2 is also expressed broadly in the striatum and corpus callosum, two areas where virtually no PBK/TOPK signal is seen. In addition, NG2 labeling in the SEZ is generally dimmer than in the striatum. Overall, our results demonstrate that PBK/TOPK is only expressed in a subset of NG2-positive cells of SEZ, perhaps representing a proliferating subset of these progenitors, and is not generally expressed in NG2-positive progenitors outside the SEZ. In summary, PBK/TOPK-expressing cells comprise the cycling $(\mathrm{MCM} 2+$; short pulse BRDU+; PCNA+) neural progenitors (MASH1+, EGFR+, Tuj1-, Dcx-, GFAP-) of the SEZ in vivo.

\section{PBK/TOPK-positive cells are mitotically active progenitors in vivo}

The expression pattern in vitro as a mitotically active kinase, coupled with in vivo data, provided evidence that PBK/TOPK was expressed in several mitotically active progenitor cell populations in the CNS but not in quiescent, slower-cycling putative stem cells. To more conclusively establish PBK/TOPK expression in stem and progenitor cells in vivo, we examined PBK/TOPK in transgenic mice expressing the herpes simplex virus thymidine kinase gene (HSV-TK) under control of the GFAP promoter (Bush et al., 1999; Garcia et al., 2004). Because HSV-TK phosphorylates the drug ganciclovir and phosphorylated ganciclovir kills cells at mitosis, when these mice are given ganciclovir, all dividing GFAP-positive cells are killed. Previous work has shown that when these mice are treated with ganciclovir, there is a complete ablation of stem cell potential, as assessed by multipotent neurosphere forming ability in vitro (Imura et al., 2003; Morshead et al., 2003) and a complete ablation of neurogenesis in vivo (Garcia et al., 2004). Three transgenic mice were treated for $21 \mathrm{~d}$ with ganciclovir followed by four BrdU injections over $2 \mathrm{~d}$ and then processed for immunohistochemistry. This treatment resulted in a complete ablation of Dcx-positive cells in SEZ (data
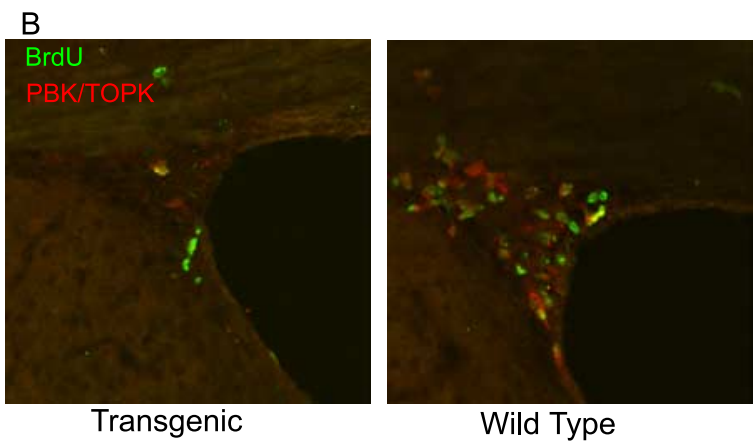

Wild Type

Figure 7. PBK/TOPK cells are dramatically reduced when stem cells are ablated. $\boldsymbol{A}$, Schematic of tissue slice showing the not shown) and an $\sim 70 \%$ reduction in $\mathrm{PBK} / \mathrm{TOPK}$-positive cells (independent samples $t$ test; $p<0.001$ ) in the SEZ, relative to nontransgenic controls. All remaining PBK/TOPK-positive cells were BrdU positive, demonstrating that they had been born after the discontinuation of ganciclovir treatment (Fig. 7), or were cycling cells not yet killed by the ganciclovir, which is lethal at mitosis. This finding provided direct in vivo evidence that $\mathrm{PBK} /$ TOPK-positive cells arise from proliferating GFAP-positive cells, consistent with $\mathrm{PBK} / \mathrm{TOPK}$ being expressed exclusively by proliferating progenitor cells in the adult brain.

This finding raised several important questions, including an apparent paradox: an ablation of GFAP-positive cells leads to ablation of PBK/TOPK-positive cells, yet, at any given point in time, we were unable to identify any cells expressing both GFAP and PBK/TOPK. These data can be reconciled by considering a lineage relationship, such that TOPK/PBK-positive cells are generated from GFAP-positive cells but represent a different stage in progenitor lineage. Based on the previous data presented, this would be consistent with the PBK/TOPK-positive cells being expressed by a rapidly proliferating, GFAP-negative, population of cells called transient amplifying, or type $\mathrm{C}$ cells, that arise from more quiescent GFAP-positive cells, as suggested previously (Morshead et al., 1994, 1998, 2003; Doetsch et al., 1997, 1999a,b).

To test this hypothesis, we used a transgenic mouse that was generated by crossing a GFAP promoter-driven CRE with a floxed-stop-enhanced green fluorescent protein (eGFP) reporter (Garcia et al., 2004). In this mouse, all progeny of cells that have ever expressed GFAP become permanently eGFP positive. Virtually all $(94.7 \pm 2.6 \% ; n=83)$ of the PBK/TOPK-positive cells in the SEZ were eGFP positive, demonstrating conclusively that they arise from GFAP-positive cells (Fig. 8), even though they are themselves GFAP negative. These data support the general model, proposed by Doetsch el al. (1997), which contains a transient amplifying progenitor cell in adult SEZ neurogenesis.

\section{Discussion}

We previously initiated studies to discover and characterize genes that could provide functional insight into neuronal progenitor proliferation and their fundamental property of self-renewal by implementing a gene expression-profiling strategy that used representational difference analysis subtraction coupled to microarray screening (Geschwind et al., 2001). We further stratified that profile with extensive screening for overlapping expression in stem cell populations and germinal zones, identifying a few key genes with enriched expression in multiple stem cell populations, 


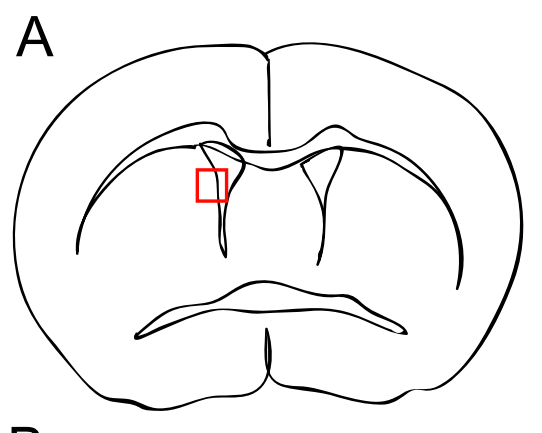

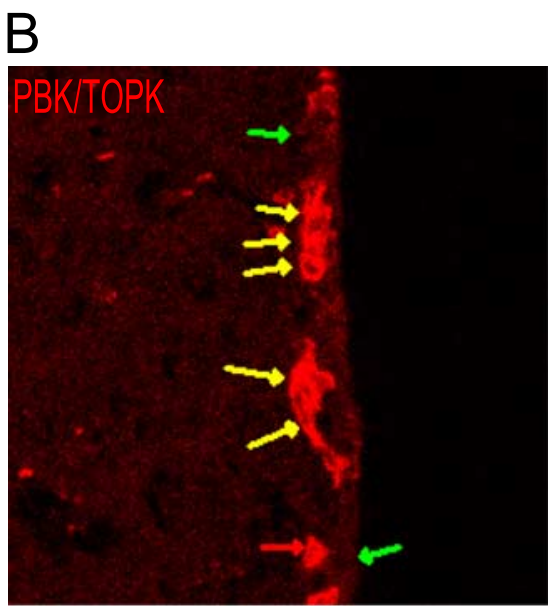
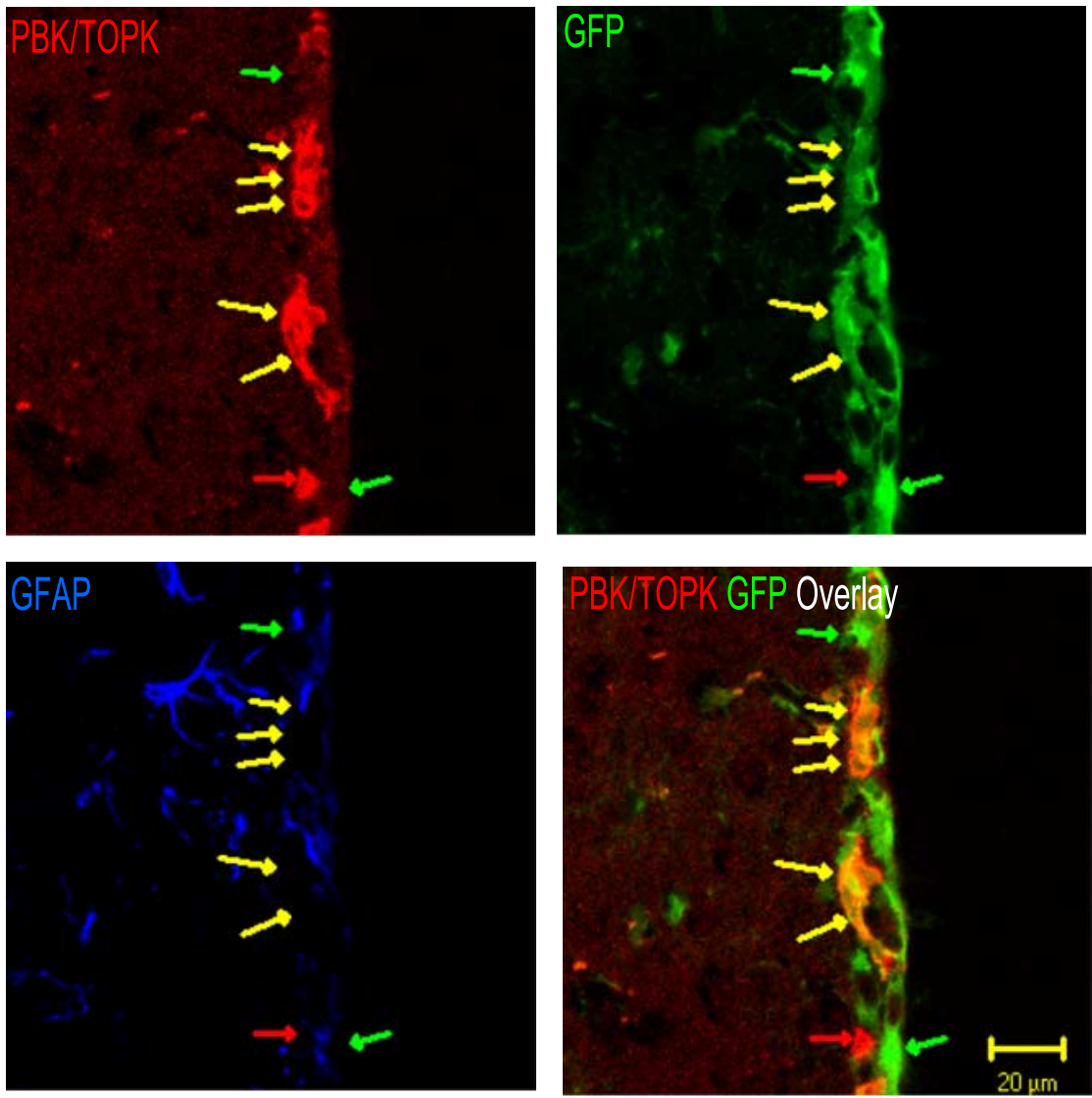

Figure 8. PBK/TOPK cells are GFAP-negative progeny of GFAP-positive cells. $A$, Schematic of tissue slice showing the location of $\boldsymbol{B}$ in the red box. $\boldsymbol{B}$, Subependymal zone from a transgenic in which all progeny of GFAP-positive cells express eGFP. Virtually all PBK/TOPK-positive cells (red) are GFAP negative (blue) but are progeny of GFAP-positive cells (green). Yellow arrows, Examples of PBK/TOPK and eGFP double-positive cells; green arrows, eGFP-positive cells; red arrows, an extremely rare PBK/TOPK singlepositive cell.

suggesting a role in progenitor self-renewal (Easterday et al., 2003). Here, we have characterized extensively one of those candidates, PBK/TOPK, a MAPKK not previously known to be involved in CNS development. We show, using in vitro models, that $\mathrm{PBK} / \mathrm{TOPK}$ is activated in a manner that suggests an important role in proliferation of progenitor populations. We also show, in vivo, that $\mathrm{PBK} / \mathrm{TOPK}$ is expressed by a specific population of proliferating progenitors in the adult brain, the transient amplifying, or type C cell (Doetsch et al., 1997), as well as identifying other activated progenitor populations in postnatal cerebellar development. These data support a role for PBK/TOPK in neural progenitor proliferation and self-renewal and, in combination with our studies of other genes (Nakano et al., 2005), supports our general genomic screening approach to identify progenitor markers.
Previous literature in non-neural cell lines and our own bioinformatic exploration using microarray data from primary neural cells suggested that PBK/TOPK was a highly regulated protein, the function of which was most likely related to the M-phase in the cell cycle. Study of its sequence conservation across phylogeny from zebrafish to human supported this by identifying a highly conserved putative cyclinB phosphorylation site. Therefore, we explored this hypothesis in vitro by examining cell-cycle regulation of PBK/ TOPK using a new phospho-specific antibody directed against the thr- 9 site that comprised the target of cyclinB/CDK1. In both cell lines and primary neuronal progenitors from the cerebellum, we demonstrate that this site is specifically phosphorylated only in mitosis and that this phosphorylation rapidly disappears in late telophase. Additionally, P38 MAPK, the target of PBK/TOPK in non-neural tissue (Abe et al., 2000), is also phosphorylated at mitosis in neural cells; P38 phosphorylation is observed only in cyclinB-positive cells, with condensed chromatin, and its appearance is enhanced by mitogen. Finally, inhibition of P38 by the specific inhibitor SB203580 decreases the proliferation of these cells, providing preliminary evidence for a functional role of this pathway in progenitor self-renewal. It remains to be seen whether inhibition or ablation of PBK/TOPK will have the same effect or whether other MAPKKs may also activate P38 in this context. It also should be emphasized that not only are these data relevant for understanding PBK/TOPK function but they provide a confirmation of the bioinformatic approach that we used to generate functional inferences. This exploratory use of published microarray data sets is likely to be generally useful for developing new hypotheses about gene function that can than be tested at the bench, as we did here.

In vivo, the current studies also provide clear evidence that neuronal progenitors and possibly multipotent progenitors express PBK/TOPK while they are proliferating. First, PBK/TOPK is strongly expressed in the mitotic layer of the external granule layer in PCNA-positive, Dcx, Tuj1, and GLASTnegative cells. This structure only gives rise to cerebellar granule neurons; thus, PBK/TOPK must be expressed in the precursors of these neurons. This is supported by data showing that purified CGP in vitro expresses PBK/TOPK, which is mitogen dependent, parallel with the $\mathrm{SSH}$ requirement for CGP proliferation (Wechsler-Reya and Scott, 1999). Indeed, in culture, PBK/TOPK expression still overlaps strongly with PCNA, a marker of proliferation, and not with NeuN, a marker of maturing neurons. Furthermore, many proliferating cells in the SEZ and RMS, structures that give rise to neurons throughout the life of the animal (Luskin, 1993), are positive for both PBK/TOPK and the proneu- 
ral Mash1 gene. Considered together, all of the evidence clearly demonstrates PBK/TOPK is expressed by multiple neuronal progenitor populations during development, and possibly multipotent progenitors as well (Parras et al., 2004).

Cytological investigations have identified three major morphologically defined populations of cells in the SEZ: ultrastructurally migrating neurons, GFAP-positive glial cells, and highly proliferative ultrastructurally immature cells (Doetsch et al., 1997; Doetsch et al., 2002). The current belief is that slow-cycling GFAP-positive cells give rise to rapidly cycling GFAP-negative progenitor cells, which then give rise to immature neurons that migrate to the olfactory bulb. This model has been supported by studies that demonstrate neurospheres must directly or indirectly arise from slow-cycling and GFAP-positive cells (Morshead et al., 1994, 1998; Doetsch et al., 1999b; Imura et al., 2003; Garcia et al., 2004). Using three different markers of proliferation, PCNA, MCM2, and short-pulse BrdU labeling, we show that PBK/TOPK cells are a highly proliferative population of cells. Using markers of migrating immature neurons, Tuj1 (Menezes et al., 1995) and Dcx, we have shown that PBK/TOPK-expressing cells are adjacent to but not overlapping with these immature neurons. Neither was there generally detectable overlap with quiescent GFAPpositive slow-cycling cells in adult animals.

These data lead to the following model for PBK/TOPK expression in the adult SEZ, illustrated in supplemental Figure 4 (available at www.jneurosci.org as supplemental material). A resting GFAP-positive cell in the SEZ enters the cell cycle and gives rise to a rapidly proliferating $\mathrm{PBK} / \mathrm{TOPK}$ - and MASH1-positive and GFAP-negative progeny. These cells then give rise to PBK/TOPKnegative, Tuj1, Dcx-positive immature neuronal progeny that migrate to the olfactory bulb to become mature neurons. This model is strongly supported by the dramatic decrease in PBK/ TOPK-positive cell number following ablation of GFAP-positive cycling cells and the lineage experiments that demonstrate that PBK/TOPK-positive cells must arise from GFAP-positive cells. These data demonstrate that the mitotic kinase PBK/TOPK is a marker of transiently amplifying, type $C$, progenitor cells in the SEZ and provide additional support for the models proposed previously (Doetsch et al., 1997, 2002).

It is also interesting to consider $\mathrm{PBK} / \mathrm{TOPK}$ expression in progenitor cells in vivo compared with its detection in stem cell cultures in vitro. Our initial screening studies to identify PBK/TOPK were done with in vitro models of stem cells (Geschwind et al., 2001; Easterday et al., 2003). Yet, in vivo, PBK/TOPK appears to be expressed in the transiently amplifying progenitor cell but not in quiescent GFAP-positive stem cells. This observation may be explained by the differences between the behavior of neural stem cells in vitro versus in vivo. First, it is currently unclear whether the transiently amplifying cells can serve as a multipotent sphere forming cell in vivo, because there are studies both supporting (Doetsch et al., 2002) and questioning (Morshead et al., 1994) this role. Second, the GFAP-positive quiescent neural stem cell may express PBK/TOPK when activated, for example by bFGF or EGF in culture. Finally, it is unclear whether the transiently amplifying cell can revert into a quiescent GFAP-positive stem cell in vivo or in vitro and whether these are two distinct cell populations or simply the same population in two different states.

Outside of the SEZ, the other predominant region of expression of PBK/TOPK is the early postnatal cerebellum. The greatest expression is seen in the mitotic portion of the external granule cell layer (EGLa). Extensive studies have shown that during this period, this region produces granule cells exclusively (Altman, 1972; Lee et al., 2005). In addition to the expression of PBK/
TOPK in the EGL, there is moderate expression of PBK/TOPK in the cerebellar white matter (data not shown) in MASH1-positive cells. Recent studies have suggested that multipotent neural stem cells may be found in this region as late as the first postnatal week (Goldman et al., 1997; Milosevic and Goldman, 2002; Lee et al., 2005). Considered together with the results of our studies in the SEZ, this suggests that PBK/TOPK is expressed by proliferating, self-renewing stem and progenitor cells throughout the brain.

The identification of PBK/TOPK as significantly enriched in this critical mitotically active, self-renewing stem and progenitor population, its regulated phosphorylation by cyclinB/cdk1 during this process, and its relationship to P38 MAPK provides another tool with which to begin to understand molecular pathways of cell-cycle regulation and their coupling to cell fate decisions in the CNS (Anderson, 2001; Ohnuma and Harris, 2003). In this regard, the enrichment of $\mathrm{PBK} / \mathrm{TOPK}$, an M-phase, cell-cyclerelated gene in a specific subpopulation of proliferating neuronal progenitor cells raises a number of interesting issues, including the issue of the role of $\mathrm{M}$-phase regulation in progenitor cell self-renewal. Furthermore, how the process of cell division may provide critical windows in which daughter cell fate or the commitment to renew are integrated with environmental signals remains a fundamental question (Lu et al., 2000). Signaling proteins such as PBK/TOPK, which are relatively cell class enriched and preferentially active in $\mathrm{M}$-phase, are poised to act as a coincidence detectors, providing a mechanism to combine extracellular signaling to intracellular state for cell fate decisions. Future studies specifically ablating PBK/TOPK expression will allow the examination of such a mechanism.

\section{References}

Abe Y, Matsumoto S, Kito K, Ueda N (2000) Cloning and expression of a novel MAPKK-like protein kinase, lymphokine-activated killer T-celloriginated protein kinase, specifically expressed in the testis and activated lymphoid cells. J Biol Chem 275:21525-21531.

Aguirre AA, Chittajallu R, Belachew S, Gallo V (2004) NG2-expressing cells in the subventricular zone are type C-like cells and contribute to interneuron generation in the postnatal hippocampus. J Cell Biol 165:575-589.

Altman J (1972) Postnatal development of the cerebellar cortex in the rat. I. The external germinal layer and the transitional molecular layer. J Comp Neurol 145:353-397.

Anderson DJ (2001) Stem cells and pattern formation in the nervous system: the possible versus the actual. Neuron 30:19-35.

Bush TG, Puvanachandra N, Horner CH, Polito A, Ostenfeld T, Svendsen CN, Mucke L, Johnson MH, Sofroniew MV (1999) Leukocyte infiltration, neuronal degeneration, and neurite outgrowth after ablation of scarforming, reactive astrocytes in adult transgenic mice. Neuron 23:297-308.

Campos CB, Bedard PA, Linden R (2002) Activation of p38 mitogenactivated protein kinase during normal mitosis in the developing retina. Neuroscience 112:583-591.

Capela A, Temple S (2002) LeX/ssea-1 is expressed by adult mouse CNS stem cells, identifying them as nonependymal. Neuron 35:865-875.

Dennis Jr G, Sherman BT, Hosack DA, Yang J, Gao W, Lane HC, Lempicki RA (2003) DAVID: database for annotation, visualization, and integrated discovery. Genome Biol 4:P3.

Doetsch F, Garcia-Verdugo JM, Alvarez-Buylla A (1997) Cellular composition and three-dimensional organization of the subventricular germinal zone in the adult mammalian brain. J Neurosci 17:5046-5061.

Doetsch F, Garcia-Verdugo JM, Alvarez-Buylla A (1999a) Regeneration of a germinal layer in the adult mammalian brain. Proc Natl Acad Sci USA 96:11619-11624.

Doetsch F, Caille I, Lim DA, Garcia-Verdugo JM, Alvarez-Buylla A (1999b) Subventricular zone astrocytes are neural stem cells in the adult mammalian brain. Cell 97:703-716.

Doetsch F, Petreanu L, Caille I, Garcia-Verdugo JM, Alvarez-Buylla A (2002) EGF converts transit-amplifying neurogenic precursors in the adult brain into multipotent stem cells. Neuron 36:1021-1034.

Easterday MC, Dougherty JD, Jackson RL, Ou J, Nakano I, Paucar AA, Roobini B, Dianati M, Irvin DK, Weissman IL, Terskikh AV, Geschwind DH, 
Kornblum HI (2003) Neural progenitor genes. Germinal zone expression and analysis of genetic overlap in stem cell populations. Dev Biol 264:309-322.

Eisen MB, Spellman PT, Brown PO, Botstein D (1998) Cluster analysis and display of genome-wide expression patterns. Proc Natl Acad Sci USA 95:14863-14868.

Freije WA, Castro-Vargas FE, Fang Z, Horvath S, Cloughesy T, Liau LM, Mischel PS, Nelson SF (2004) Gene expression profiling of gliomas strongly predicts survival. Cancer Res 64:6503-6510.

Furuta A, Rothstein JD, Martin LJ (1997) Glutamate transporter protein subtypes are expressed differentially during rat CNS development. J Neurosci 17:8363-8375.

Gage FH (2000) Mammalian neural stem cells. Science 287:1433-1438.

Gallagher TF, Seibel GL, Kassis S, Laydon JT, Blumenthal MJ, Lee JC, Lee D, Boehm JC, Fier-Thompson SM, Abt JW, Soreson ME, Smietana JM, Hall RF, Garigipati RS, Bender PE, Erhard KF, Krog AJ, Hofmann GA, Sheldrake PL, McDonnell PC, Kumar S, Young PR, Adams JL (1997) Regulation of stress-induced cytokine production by pyridinylimidazoles; inhibition of CSBP kinase. Bioorg Med Chem 5:49-64.

Galli R, Binda E, Orfanelli U, Cipelletti B, Gritti A, De Vitis S, Fiocco R, Foroni C, Dimeco F, Vescovi A (2004) Isolation and characterization of tumorigenic, stem-like neural precursors from human glioblastoma. Cancer Res 64:7011-7021.

Garcia AD, Doan NB, Imura T, Bush TG, Sofroniew MV (2004) GFAPexpressing progenitors are the principal source of constitutive neurogenesis in adult mouse forebrain. Nat Neurosci 7:1233-1241.

Gaudet S, Branton D, Lue RA (2000) Characterization of PDZ-binding kinase, a mitotic kinase. Proc Natl Acad Sci USA 97:5167-5172.

Geschwind DH, Ou J, Easterday MC, Dougherty JD, Jackson RL, Chen Z, Antoine H, Terskikh A, Weissman IL, Nelson SF, Kornblum HI (2001) A genetic analysis of neural progenitor differentiation. Neuron 29:325-339.

Goldman JE, Zerlin M, Newman S, Zhang L, Gensert J (1997) Fate determination and migration of progenitors in the postnatal mammalian CNS. Dev Neurosci 19:42-48.

Guillemot F (1995) Analysis of the role of basic-helix-loop-helix transcription factors in the development of neural lineages in the mouse. Biol Cell 84:3-6.

Hemmati HD, Nakano I, Lazareff JA, Masterman-Smith M, Geschwind DH, Bronner-Fraser M, Kornblum HI (2003) Cancerous stem cells can arise from pediatric brain tumors. Proc Natl Acad Sci USA 100:15178-15183.

Hosack DA, Dennis Jr G, Sherman BT, Lane HC, Lempicki RA (2003) Identifying biological themes within lists of genes with EASE. Genome Biol 4:R70.

Ignatova TN, Kukekov VG, Laywell ED, Suslov ON, Vrionis FD, Steindler DA (2002) Human cortical glial tumors contain neural stem-like cells expressing astroglial and neuronal markers in vitro. Glia 39:193-206.

Imura T, Kornblum HI, Sofroniew MV (2003) The predominant neural stem cell isolated from postnatal and adult forebrain but not early embryonic forebrain expresses GFAP. J Neurosci 23:2824-2832.

Karsten SL, Kudo LC, Jackson R, Sabatti C, Kornblum HI, Geschwind DH (2003) Global analysis of gene expression in neural progenitors reveals specific cell-cycle, signaling, and metabolic networks. Dev Biol 261:165-182.

Krishan A (1975) Rapid flow cytofluorometric analysis of mammalian cellcycle by propidium iodide staining. J Cell Biol 66:188-193.

Lee A, Kessler JD, Read TA, Kaiser C, Corbeil D, Huttner WB, Johnson JE, Wechsler-Reya RJ (2005) Isolation of neural stem cells from the postnatal cerebellum. Nat Neurosci 8:723-729.

Lendahl U, Zimmerman LB, McKay RD (1990) CNS stem cells express a new class of intermediate filament protein. Cell 60:585-595.

Li C, Wong WH (2001) Model-based analysis of oligonucleotide arrays: expression index computation and outlier detection. Proc Natl Acad Sci USA 98:31-36.

Lie DC, Song H, Colamarino SA, Ming GL, Gage FH (2004) Neurogenesis in the adult brain: new strategies for central nervous system diseases. Annu Rev Pharmacol Toxicol 44:399-421.

Lindvall O, Kokaia Z, Martinez-Serrano A (2004) Stem cell therapy for human neurodegenerative disorders-how to make it work. Nat Med 10 [Suppl]:S42-S50.

Lu B, Jan L, Jan YN (2000) Control of cell divisions in the nervous system: symmetry and asymmetry. Annu Rev Neurosci 23:531-556.

Luskin MB (1993) Restricted proliferation and migration of postnatally generated neurons derived from the forebrain subventricular zone. Neuron 11:173-189.

Maslov AY, Barone TA, Plunkett RJ, Pruitt SC (2004) Neural stem cell detection, characterization, and age-related changes in the subventricular zone of mice. J Neurosci 24:1726-1733.

Matsumoto S, Abe Y, Fujibuchi T, Takeuchi T, Kito K, Ueda N, Shigemoto K,
Gyo K (2004) Characterization of a MAPKK-like protein kinase TOPK. Biochem Biophys Res Commun 325:997-1004.

Menezes JR, Smith CM, Nelson KC, Luskin MB (1995) The division of neuronal progenitor cells during migration in the neonatal mammalian forebrain. Mol Cell Neurosci 6:496-508.

Migheli A, Piva R, Casolino S, Atzori C, Dlouhy SR, Ghetti B (1999) A cell-cycle alteration precedes apoptosis of granule cell precursors in the weaver mouse cerebellum. Am J Pathol 155:365-373.

Miki R, Kadota K, Bono H, Mizuno Y, Tomaru Y, Carninci P, Itoh M, Shibata K, Kawai J, Konno H, Watanabe S, Sato K, Tokusumi Y, Kikuchi N, Ishii Y, Hamaguchi Y, Nishizuka I, Goto H, Nitanda H, Satomi S, et al. (2001) Delineating developmental and metabolic pathways in vivo by expression profiling using the RIKEN set of 18,816 full-length enriched mouse cDNA arrays. Proc Natl Acad Sci USA 98:2199-2204.

Milosevic A, Goldman JE (2002) Progenitors in the postnatal cerebellar white matter are antigenically heterogeneous. J Comp Neurol 452:192-203.

Morshead CM, van der Kooy D (2004) Disguising adult neural stem cells Curr Opin Neurobiol 14:125-131.

Morshead CM, Reynolds BA, Craig CG, McBurney MW, Staines WA, Morassutti D, Weiss S, van der Kooy D (1994) Neural stem cells in the adult mammalian forebrain: a relatively quiescent subpopulation of subependymal cells. Neuron 13:1071-1082.

Morshead CM, Craig CG, van der Kooy D (1998) In vivo clonal analyses reveal the properties of endogenous neural stem cell proliferation in the adult mammalian forebrain. Development 125:2251-2261.

Morshead CM, Garcia AD, Sofroniew MV, van Der Kooy D (2003) The ablation of glial fibrillary acidic protein-positive cells from the adult central nervous system results in the loss of forebrain neural stem cells but not retinal stem cells. Eur J Neurosci 18:76-84.

Murray RC, Navi D, Fesenko J, Lander AD, Calof AL (2003) Widespread defects in the primary olfactory pathway caused by loss of Mash1 function. J Neurosci 23:1769-1780.

Nakano I, Paucar AA, Bajpai R, Dougherty JD, Zewail A, Kelly TK, Kim KJ, Ou J, Groszer M, Imura T, Freije WA, Nelson SF, Sofroniew MV, Wu H Liu X, Terskikh AV, Geschwind DH, Kornblum HI (2005) Maternal embryonic leucine zipper kinase (MELK) regulates multipotent neural progenitor proliferation. J Cell Biol 170:413-427.

Ohnuma S, Harris WA (2003) Neurogenesis and the cell cycle. Neuron 40:199-208.

Palmer TD, Markakis EA, Willhoite AR, Safar F, Gage FH (1999) Fibroblast growth factor-2 activates a latent neurogenic program in neural stem cells from diverse regions of the adult CNS. J Neurosci 19:8487-8497.

Parras CM, Galli R, Britz O, Soares S, Galichet C, Battiste J, Johnson JE, Nakafuku M, Vescovi A, Guillemot F (2004) Mash1 specifies neurons and oligodendrocytes in the postnatal brain. EMBO J 23:4495-4505.

Ren B, Robert F, Wyrick JJ, Aparicio O, Jennings EG, Simon I, Zeitlinger J, Schreiber J, Hannett N, Kanin E, Volkert TL, Wilson CJ, Bell SP, Young RA (2000) Genome-wide location and function of DNA binding proteins. Science 290:2306-2309.

Reynolds BA, Weiss S (1992) Generation of neurons and astrocytes from isolated cells of the adult mammalian central nervous system. Science 255:1707-1710.

Simons-Evelyn M, Bailey-Dell K, Toretsky JA, Ross DD, Fenton R, Kalvakolanu D, Rapoport AP (2001) PBK/TOPK is a novel mitotic kinase which is upregulated in Burkitt's lymphoma and other highly proliferative malignant cells. Blood Cells Mol Dis 27:825-829.

Singh SK, Clarke ID, Terasaki M, Bonn VE, Hawkins C, Squire J, Dirks PB (2003) Identification of a cancer stem cell in human brain tumors. Cancer Res 63:5821-5828.

Terskikh AV, Easterday MC, Li L, Hood L, Kornblum HI, Geschwind DH, Weissman IL (2001) From hematopoiesis to neuropoiesis: evidence of overlapping genetic programs. Proc Natl Acad Sci USA 98:7934-7939.

Tsurimoto T (1999) PCNA binding proteins. Front Biosci 4:D849-D858.

Wechsler-Reya RJ, Scott MP (1999) Control of neuronal precursor proliferation in the cerebellum by Sonic Hedgehog. Neuron 22:103-114.

Whitfield ML, Sherlock G, Saldanha AJ, Murray JI, Ball CA, Alexander KE, Matese JC, Perou CM, Hurt MM, Brown PO, Botstein D (2002) Identification of genes periodically expressed in the human cell-cycle and their expression in tumors. Mol Biol Cell 13:1977-2000.

Yuryev A, Wennogle LP (2003) Novel raf kinase protein-protein interactions found by an exhaustive yeast two-hybrid analysis. Genomics 81:112-125.

Zhao S, Dai J, Zhao W, Xia F, Zhou Z, Wang W, Gu S, Ying K, Xie Y, Mao Y (2001) PDZ-binding kinase participates in spermatogenesis. Int J Biochem Cell Biol 33:631-636. 